\title{
Hydrodynamic modelling of coastal seas: the role of tidal dynamics in the Messina Strait, Western Mediterranean Sea
}

\author{
Andrea Cucco, Giovanni Quattrocchi, Antonio Olita, Leopoldo Fazioli, Alberto Ribotti, Matteo Sinerchia, \\ Costanza Tedesco, and Roberto Sorgente \\ National Research Council, Institute for Coastal Marine Environment, Loc. Sa Mardini, Torregrande, Oristano, 09170 Italy \\ Correspondence to: Andrea Cucco (andrea.cucco@cnr.it)
}

Received: 7 March 2016 - Published in Nat. Hazards Earth Syst. Sci. Discuss.: 14 March 2016

Revised: 27 May 2016 - Accepted: 17 June 2016 - Published: 6 July 2016

\begin{abstract}
This work explores the importance of considering tidal dynamics when modelling the general circulation in the Messina Strait, a narrow passage connecting the Tyrrhenian and the Ionian subbasins in the Western Mediterranean Sea. The tides and the induced water circulation in this Strait are among the most intense oceanographic processes in the Mediterranean Sea. The quantification of these effects can be particularly relevant for operational oceanographic systems aimed to provide short-term predictions of the main hydrodynamics in the Western Mediterranean subbasins. A numerical approach based on the use of a high-resolution hydrodynamic model was followed to reproduce the tides propagation and the wind-induced and thermohaline water circulation within the Strait and in surrounding areas. A set of numerical simulations was carried out to quantify the role of the Strait dynamics on the larger-scale water circulation. The obtained results confirmed the importance of a correct representation of the hydrodynamics in the Messina Strait even when focusing on predicting the water circulation in the external sea traits. In fact, model results show that tidal dynamics deeply impact the reproduction of the instantaneous and residual circulation pattern, waters thermohaline properties and transport dynamics both inside the Messina Strait and in the surrounding coastal and open waters.
\end{abstract}

\section{Introduction}

In the XII chapter of the Odyssey, before the landing to Trinacria Island, Ulysses and his crew leaving the Circe refuge, experienced the wrath of Scylla and Charybdis, with great loss of men and ships (Homer, VI B.C.). Homer's poem, de- scribing the intense vortices and heavy currents generated by the tides (Scylla and Charybdis) in the Messina Strait (Western Mediterranean Sea, hereafter MS), can be considered as one of the first examples of grey literature in physical oceanography.

The tides and the induced water circulation in this Strait (Fig. 1a and b) are among the most interesting oceanographic processes in the Mediterranean Sea, and not only because of Homer's epic.

The intense current speeds and the high variability of tidal phases and frequencies lead us to consider this area as one of the most energetic in terms of momentum and impulse all over the basin (Hopkins et al., 1984). This is why, in recent years, several research activities were carried out to investigate how tidal dynamics in this area can be exploited to produce renewable energy (Coiro et al., 2013).

Although notorious, the dynamic of the Strait is not fully addressed in scientific literature, with only few and old studies describing the water circulation in both theoretical and experimental terms (Hopkins et al., 1984; Cescon et al., 1997) and very few recent investigations using numerical modelling techniques (Androsov et al., 2002a, b). In particular, while tidal dynamic inside the Strait has been studied and described by many authors starting from the early XX century (Vercelli, 1925, 1926; Defant, 1940, 1961; Bossolasco and Dagnino, 1957; Massi and Sallusti, 1979; Mosetti, 1988), the effects of the Messina tidal in- and outflow on the outer open ocean thermohaline water circulation are still unaddressed in scientific literature. In particular, both recent and old studies focused mainly on describing the behaviour of Tyrrhenian and Ionian waters flowing through the Strait (Bossolasco and Dagnino, 1959; Androsov et al., 2002b) and on the gener- 

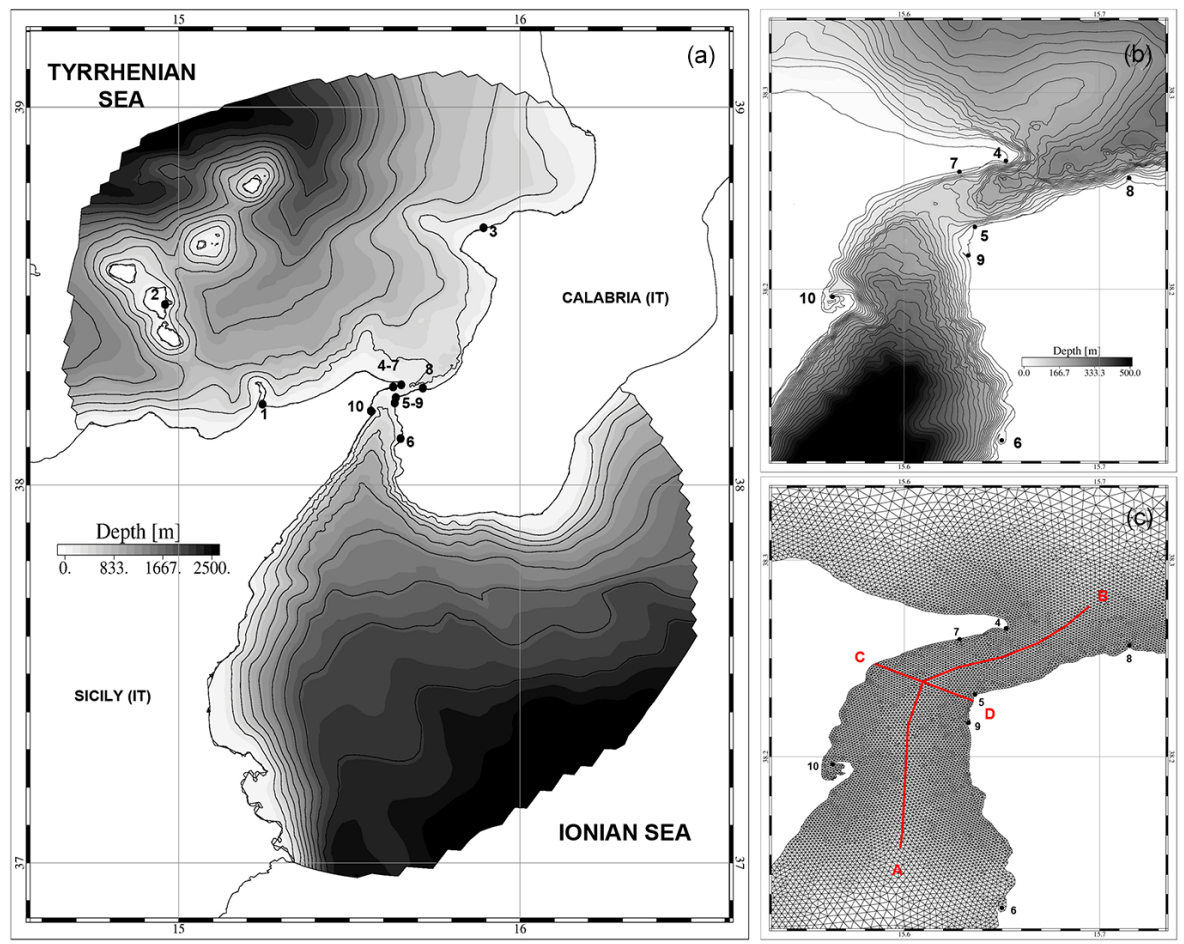

Figure 1. (a) Geographical settings and model domain: investigated area comprising the Messina Strait, the southern Tyrrhenian Sea and part of Ionian Sea; geometry and bathymetry. Black dots and numbers indicate the tide gauge locations at Milazzo (1), Lipari (2) Tropea (3), Faro (4), Punta Pezzo (5), Reggio (6), Messina (7), Ganzirri (8), Villa S. Giovanni (9) and Messina (10). (b) Zoom of the Messina Strait. (c) Zoom of the finite element mesh adopted for numerical simulations. Red lines from A to B and from C to D indicate the sections used for the flux computation and model results analysis.

ation of internal waves (Brandt et al., 1997, 1999) without quantifying the role of MS tidal dynamics in modifying the outer circulation pattern.

The quantification of these effects can be particularly relevant for operational oceanographic systems aimed to provide short-term predictions of the main hydrodynamics in the Western Mediterranean subbasins. Most of these ocean prediction systems (Tonani et al., 2008, 2015; Oddo et al., 2009; Pinardi et al., 2010; Sorgente et al., 2011) are not suitable to accurately reproduce the Strait dynamics mainly due to numerical grid limitation, such as orthogonality and spatial resolution generally not appropriate to describe the fine scale coastal features. As a consequence, their operational outputs, including water temperature, salinity and currents fields, are produced ignoring the contribution of the tidal exchanges within the Strait which can be capable of modifying the aforementioned fields as well as the water mass budgets between the subbasins.

Consequently, the question is how big the effect of accurately capturing the tidal dynamics and the finer scale processes is on the model reproduction of the general circulation in this area. This issue is particularly relevant in the case of MS, which is characterized by intense tidal dynamics (quite a unique case in the Mediterranean Sea), where tides are gen- erally weak and have a low influence on the circulation (Sannino et al., 2015).

In this work, a numerical approach using a high-resolution hydrodynamic model based on finite elements method was proposed to reproduce both the tidal propagation and the wind-induced and thermohaline circulation in the Strait and surrounding areas and to quantify the role of the Strait dynamics on the outer water circulation. Three different scenarios, characterized by different model forcings, were investigated in order to identify the weight of each single contribution (tides, thermohaline and wind) to the main hydrodynamics in the area of interest.

The paper is organised as follows: a brief description of the MS study area, including the morphological and oceanographic features, is reported in Sect. 2. An overview of the applied methods including the description of the adopted numerical model and of the three simulated scenarios is reported in Sect. 3. In Sect. 4, the differences between the three scenarios results are analysed highlighting the importance of reproducing the tidal dynamics in the MS. Finally in Sect. 5, the concluding remarks are presented. 


\section{The study site}

The Messina Strait (Fig. 1a, b) is a narrow and deep channel connecting two Mediterranean subbasins: the Tyrrhenian and the Ionian Sea. The Strait is comprised approximately between $37.9-38.3^{\circ} \mathrm{N}$ and $15.3-15.8^{\circ} \mathrm{E}$, it is about $60 \mathrm{~km}$ long, and $10 \mathrm{~km}$ wide with the narrowest passage of about $3 \mathrm{~km}$ width. The main axis is north to south oriented slightly bending eastward in proximity of the northern opening. The water depth at the mouths of the Strait varies between 500 and $600 \mathrm{~m}$, abruptly decreasing to $100 \mathrm{~m}$ in the vicinity of the sill in the narrowest passage.

The astronomic tides represent the main forcing driving the water circulation inside the MS, which occurs mainly along the major axis. The water vertical displacement varies between 0.2 and $0.3 \mathrm{~m}$, which are the typical values of tidal amplitudes in the Western Mediterranean Sea. Despite the very low amplitudes, the water flow inside the Strait is very intense reaching up to $2.5 \mathrm{~m} \mathrm{~s}^{-1}$ during the spring tides. The tidal frequency is mainly semidiurnal, with the M2 and S2 being the most intense constituents, but also with a strong contribution due to the over-tides M4, which are generated by the nonlinear interaction between the semidiurnal constituents and between the tidal waves and the complex Strait topography (Carta et al., 2008).

The flow inside the Strait is directed northward during the flood phase and southward during the ebb phase. The interaction between the intense currents and the channel topography and bathymetry gives rise to the formation of inertial eddies and strong horizontal current shears generally located at the lee sides of both Sicily and Calabria main capes.

The Strait connects two subbasins with different oceanographic features. The northern part of the Strait opens on the Southern Tyrrhenian Sea which is characterized by the presence of a west to east flow located between 50 and $200 \mathrm{~m}$, carrying the surface Atlantic water toward the northern part of the subbasin moving geostrophically along the Italian coast (Krivosheya, 1983; Astraldi and Gasparini, 1994; Millot, 1999; Vetrano et al., 2004). The Southern part of the Strait opens on the Western Ionian Sea characterized by a surface flow carrying the Ionian waters from the southern Calabria coastlines along the eastern side of Sicily coastlines southward to the Sicily channel.

\section{Methodology}

The tidal dynamics and the water exchange in the Messina Strait and their influence on the general water circulation in the Southern Tyrrhenian and Ionian Sea are investigated following a numerical approach.

A high-resolution hydrodynamic model (SHYFEM, hereafter; Umgiesser et al., 2004), based on the finite element method applied to Messina Strait, Southern Tyrrhenian Sea and part of the Ionian Sea was adopted to reproduce the main hydrodynamic inside the Strait and in the surrounding open sea areas. This model is part of the operational system MeSOS (Messina Strait Operational System), developed under the framework of TESSA (Technologies for the Situational Sea Awareness) project funded by the Italian Ministry for Environment, aiming to develop an innovative operational platform for the sea awareness in the Mediterranean Sea.

SHYFEM was nested into a lower-resolution open ocean model, the Tyrrhenian Sicily Channel sub-Regional Model (TSCRM, hereafter) applied to the whole Tyrrhenian Sea and Sicily Channel in order to properly account for the lateral open boundary conditions.

The TSCRM sub-regional ocean model covers the area from 8.98 to $16.5^{\circ} \mathrm{E}$ in longitude and from 31 to $43^{\circ} \mathrm{N}$ in latitude with a full three-dimensional implementation of the Princeton Ocean Model (Blumberg and Mellor, 1987; Mellor, 1991) and represents the updated version of the previous operational analysis/forecast model, named Sicily Channel sub-Regional Model (SCRM), operational since 2004 (Fazioli et al., 2016). The model uses uniform horizontal orthogonal grid with a resolution of $1 / 48^{\circ}(2 \mathrm{~km})$ in longitude and latitude $(362 \times 578$ mesh points respectively). The vertical direction is discretized by 30 sigma levels, which are spaced using a logarithmic distribution near the surface and uniformly in the rest of the water column. Surface boundary conditions are provided by ECMWF meteorological forecasting system. TSCRM assimilates AVISO data along track Sea Level Anomalies on a daily basis through a 3D Variational procedure (see OCEANVAR in Dobricic et al., 2008), with the same implementation described in Olita et al. (2012) for the previous version of the TSCRM operational system (SCRM, Gabersek et al., 2007). The system predicts, on hourly frequency, water currents, temperature and salinity at different water depths and for a 5 days time lag.

The nesting between SHYFEM and TSCRM was carried out following the procedure in Cucco et al. (2012a, b) which allows to reproduce in high details both the outer general circulation and the coastal hydrodynamics (Melaku et al., 2015; Marras et al., 2015).

The following section provides a description of SHYFEM, the numerical core of the system, its application to the MS, the adopted set-up and the three numerical experiments performed to achieve the proposed objectives.

\subsection{The hydrodynamic model}

SHYFEM is a 3-D hydrodynamic model based on the finite element method that resolves the shallow water equations integrated over each layer in their formulations with water levels and transports. The model has been applied with success in several applications and case studies in the Mediterranean Sea basin aimed to investigate and predict both open ocean and coastal hydrodynamics and to evaluate their mutual interactions (Bellafiore et al., 2008, 2011; Cucco et al., 2009; 
Melaku et al., 2012; Ferrarin et al., 2013a, 2014; Simeone et al., 2014; Umgiesser et al., 2014; Cucco and Umgiesser, 2015; Quattrocchi et al., 2016; Cucco et al., 2016).

It uses finite elements for horizontal spatial discretizations, $z$ layers for vertical discretizations and a semi-implicit algorithm for integration in time. The horizontal diffusion, the baroclinic pressure gradients and the advective terms in the momentum equation are fully explicit. The Coriolis force and the barotropic pressure gradients terms in the momentum equation and the divergence term in the continuity equation are semi-implicitly treated, while the vertical stress and friction terms are fully implicit for stability reasons. The model is unconditionally stable for fast gravity waves, bottom friction and Coriolis acceleration. The solved equation system reads as

$$
\begin{aligned}
& \frac{\partial U_{1}}{\partial t}+\mathrm{Adv}_{1}^{x}-f V_{1}=g h_{1} \frac{\partial \zeta}{\partial x}-\frac{g h_{1}}{\rho_{0}} \frac{\partial}{\partial x} \int_{-H_{\mathrm{l}}}^{\zeta} \rho^{\prime} d z \\
& +\frac{h_{1}}{\rho_{0}} \frac{\partial p_{\mathrm{a}}}{\partial x}+\frac{1}{\rho_{0}}\left(\tau_{x}^{\text {top }(1)}-\tau_{x}^{\text {bottom }(1)}\right)+A_{\mathrm{h}}\left(\frac{\partial^{2} U_{1}}{\partial x^{2}}+\frac{\partial^{2} U_{1}}{\partial y^{2}}\right) \\
& +S_{1}^{x}+\frac{\partial}{\partial z}\left(\frac{K_{1}}{h_{1}} \frac{\partial U_{1}}{\partial z}\right)+g h_{1} \frac{\partial \eta}{\partial x}-g h_{1} \beta \frac{\partial \zeta}{\partial x} \\
& \frac{\partial V_{1}}{\partial t}+\operatorname{Adv}_{1}^{y}+f U_{1}=g h_{1} \frac{\partial \zeta}{\partial y}-\frac{g h_{1}}{\rho_{0}} \frac{\partial}{\partial y} \int_{-H_{1}}^{\zeta} \rho^{\prime} d z+\frac{h_{1}}{\rho_{0}} \frac{\partial p_{\mathrm{a}}}{\partial y} \\
& +\frac{1}{\rho_{0}}\left(\tau_{y}^{\text {top }(1)}-\tau_{y}^{\text {bottom }(1)}\right)+A_{\mathrm{h}}\left(\frac{\partial^{2} V_{1}}{\partial x^{2}}+\frac{\partial^{2} V_{1}}{\partial y^{2}}\right) \\
& +S_{1}^{y}+\frac{\partial}{\partial z}\left(\frac{K_{1}}{h_{1}} \frac{\partial V_{1}}{\partial z}\right)+g h_{1} \frac{\partial \eta}{\partial y}-g h_{1} \beta \frac{\partial \zeta}{\partial y} \\
& \frac{\partial \zeta}{\partial t}+\sum_{l} \frac{\partial U_{1}}{\partial x}+\sum_{l} \frac{\partial V_{1}}{\partial y}=0,
\end{aligned}
$$

where 1 indicates the vertical layer, $\left(U_{1}, V_{1}\right)$ the horizontal transport components in $x$ and $y$ directions for each layer, $\mathrm{Adv}^{x}$ and $\mathrm{Adv}^{y}$ the advective terms, $f$ the Coriolis parameter, $p_{\mathrm{a}}$ the atmospheric pressure, $g$ the gravitational constant, $\zeta$ the water level, $\rho_{0}$ the standard water density, $p=p_{0}+p^{\prime}$ the water density, $h_{1}$ the layer thickness, $H_{1}$ the depth of the bottom of the layer $l$ and $A_{\mathrm{h}}$ the horizontal eddy viscosity estimated following the Smagorinsky parameterization (Smagorinsky, 1963: Blumberg and Mellor, 1987).

The GOTM (General Ocean Turbulence Model), a turbulence closure model described in Burchard and Petersen (1999), was used for the computation of the vertical viscosity $K_{1}$. Equilibrium tidal potential $(\eta)$ and load tides are included as model forcing. The term $\eta$ is computed as the sum of the tidal potential of each tidal constituents multiplied by the frequency-dependent elasticity factor (Kantha and Clayson, 2000), whereas the factor $\beta$ accounts for the effects of load tides (Kantha, 1995). Wind and bottom friction terms, corresponding to the boundary conditions of the stress terms $\left(\tau_{x}, \tau_{y}\right)$, are defined as

$$
\begin{aligned}
& \tau_{x}^{\text {surface }}=c_{D} \rho_{\mathrm{a}} w_{x} \sqrt{w_{x}^{2}+w_{y}^{2}} \\
& \tau_{x}^{\text {bottom }}=c_{B} \rho_{0} u_{L} \sqrt{u_{L}^{2}+v_{L}^{2}} \\
& \tau_{y}^{\text {surface }}=c_{D} \rho_{\mathrm{a}} w_{y} \sqrt{w_{x}^{2}+w_{y}^{2}} \\
& \tau_{y}^{\text {bottom }}=c_{B} \rho_{0} v_{L} \sqrt{u_{L}^{2}+v_{L}^{2}},
\end{aligned}
$$

with $C_{\mathrm{D}}$ as the wind drag coefficient, $C_{\mathrm{B}}$ the bottom friction coefficient, $\rho_{\mathrm{a}}$ the air density, $\left(w_{x}, w_{y}\right)$ the wind velocity components and $\left(u_{L}, v_{L}\right)$ the bottom velocity components.

The hydrodynamic model is coupled with an advection and diffusion numerical module that takes into account the salt and thermal balance equations to simulate the transport of both passive tracers and the salinity and temperature in the domain. Details of numerical treatment are reported in Umgiesser et al. (2004).

\subsection{Model and simulation set-up}

SHYFEM uses finite elements unstructured mesh for representing the model domain. A grid composed of about 23000 nodes and 45000 triangular elements was implemented. The mesh reproduces the MS, the south-eastern Tyrrhenian Sea and part of the western Ionian Sea. In Fig. 1a, the extent of the model domain is depicted by the area with the bathymetric details. The elements size and shape distribution is modulated accounting for both the distance from the MS and the basin morphological features. In particular, the spatial resolution varies between $50 \mathrm{~m}$ inside the MS and $2 \mathrm{~km}$ in the outer areas, corresponding to the mesh size of the TSCRM open ocean model (Fig. 1c).

Two open boundaries were defined at the northern and southern mesh borders located in the inner Tyrrhenian Sea and in the Ionian Sea respectively (Fig. 1a). The model domain was vertically discretized with 30 zeta levels ranging between 5 and $800 \mathrm{~m}$. At the closed boundaries, only the normal velocity is set to 0 , whereas the tangential velocity is a free parameter corresponding to a full slip conditions. The same model parameter set-up defined in Ferrarin et al. (2013b) was adopted.

Three different simulations, with three different set-ups defining three different scenarios, were carried out. In the first scenario (Tide Only, TDO, hereafter), SHYFEM was used to reproduce the tidal propagation in the MS and surrounding areas.

In the second scenario (atmospheric and thermohaline forcing only; THO, hereafter), the model was used to reproduce the wind-induced and thermohaline circulation in the area by downscaling the sub-regional model (TSCRM) solutions to the high-resolution model (SHYFEM) domain.

In the third scenario (tide, thermohaline and atmospheric contributions; TTC, hereafter), SHYFEM was used to reproduce the general circulation in the area induced by both ther- 
Table 1. SHYFEM forcing data, including open boundary conditions (OBC) and surface boundary conditions (SBC) adopted in the three numerical experiments TDO, THO and TTC.

\begin{tabular}{llll}
\hline & \multicolumn{3}{c}{ Scenarios set-up and model forcing } \\
\cline { 2 - 4 } & TDO & THO & TTC \\
\hline OBC & Astronomic tides & Ocean data $(T, S, u, v, \eta)$ from TSCRM & Ocean data $(T, S, u, v, \eta)$ from TSCRM and astronomic tides \\
SBC & - & Wind data, heat fluxes from ECMWF & Wind data, heat fluxes from ECMWF \\
\hline
\end{tabular}

mohaline and wind forcing and by astronomic tides. For all scenarios, simulations referred to the period between 1 January 2014 and 31 December 2015.

In Table 1, the summary of the forcing data adopted for the three scenarios is provided. Open boundary conditions for TDO scenario consisted in a set of 2-year time series of hourly water levels data extracted from a regional tidal model of the Mediterranean and Black Sea (http://volkov.oce.orst. edu/tides/otps.html).

For THO scenario, the open boundary conditions consisted in a set of hourly time series of water levels, temperature $(T)$ and salinity $(S)$, computed by TSCRM for the considered period for each SHYFEM boundaries node and at each vertical level. Meteorological forcing, including wind, precipitation and thermal fluxes reanalysed data, were provided at $6 \mathrm{~h}$ frequency by ECMWF forecasting system.

Similarly, for the TTC scenario, the same ocean and meteorological data were used as open boundary conditions with the exception of the water levels which, in this case, were derived for each point of the mesh by the sum of the tidal elevations (adopted in TDO scenario) and the sea surface elevations computed by TSCRM (adopted in THO scenario).

\section{Results and discussion}

The model was applied to simulate the 3-D water circulation and the $T$ and $S$ variability inside the MS and in the surrounding sea areas under the three described scenarios: TDO, THO and TTC. The obtained results were analysed to quantify the influence of the different forcings on the hydrodynamics of the Strait and outer sea areas.

In the following, in the first part, the tidal dynamic inside the MS, as reproduced by the TDO scenario, was described in terms of water currents, fluxes and residual circulation. Subsequently, the role of the tides in modulating the windinduced and thermohaline circulation was investigated both inside and outside the MS by comparing the THO and TTC scenarios results. Residual circulation, water fluxes, temperature and salinity distribution inside and outside the Strait as well as the transport properties were computed to quantify the influence of the tidal forcings.

Two different sections inside the MS, A-B and C-D, in Fig. 1c were used to compute the fluxes through the Strait and to investigate the vertical variability of the main hydrodynamics.

\subsection{Tidal dynamics in MS}

In the TDO scenario, SHYFEM was applied to reproduce the propagation of tides inside the MS and surrounding areas. The water levels computed at the tidal stations both outside (stations 1, 2 and 3 in Fig. 1a) and inside the Strait (stations form 4 to 10 in Fig. 1b) were compared with observations to estimate the model accuracy in predicting the tidal waves propagation in the domain.

For each station, harmonic analysis was applied to extract the amplitudes and phases of each main tidal constituent. The main harmonics observed amplitudes and phases were estimated by Vercelli (1925) during the homonym oceanographic cruise in 1922 and more recently reported by Brandolini et al. (1980) and Androsov et al. (2002a). In this work we refer to the values from Brandolini et al. (1980) for stations from 1 to 6 and from Androsov et al. (2002a) for stations from 7 to 10 . We considered the tidal signals as composed by four semidiurnal waves (M2, S2, N2 and K2), by three diurnal waves (K1, O1 and P1) and by the M4 as compound tide, which are the major components of the tides in the Mediterranean Sea and in the MS (Vercelli, 1925; Sannino et al., 2014).

In Table 2, the computed and observed amplitudes and phases of the main components are reported. For stations inside the MS most of tidal energy, around $40 \%$ of the total amplitude, is contained in the M2-wave, around $19 \%$ in the S2-wave and around the $14 \%$ of the total energy in the K1-wave. The obtained results are in line with the observed energy balance, in which M2-wave accounted for $38 \%$, S2wave for $16 \%$ and $\mathrm{K} 1$ for $13 \%$ of the total water level.

Considering the amplitude of the M2-wave, the root mean square error (RMSE) between model results and observations computed for the whole set of stations was on average about $1.7 \mathrm{~cm}$ with discrepancies ranging between 0.1 and $3.3 \mathrm{~cm}$. As for the amplitudes, also the computed phases mainly agree with observations, with average discrepancies between model results and observed values estimated to be around $40^{\circ}$. The model results highlight an anticlockwise propagation of the main semidiurnal with the presence of an amphidromic point in the middle of the Strait in the vicinity of the sill in front of Punta Pezzo (station 5). The amplitudes 
Table 2. Amplitude and phase of main harmonics observed $(o)$ and computed $(m)$ from calibrated model results in TDO scenario at the 10 tide gauge locations. Observed values for stations from 1 to 6 refer to Brandolini et al. (1980) for stations from 7 to 10 refer to Androsov et al. (2002a). Both authors refer to Vercelli (1925).

\begin{tabular}{|c|c|c|c|c|c|c|c|c|c|c|c|c|c|c|c|c|c|}
\hline & \multirow{3}{*}{ Stations } & \multicolumn{16}{|c|}{ Amplitude (cm) } \\
\hline & & \multicolumn{2}{|c|}{ M2 } & \multicolumn{2}{|c|}{$\mathrm{S} 2$} & \multicolumn{2}{|c|}{$\mathrm{N} 2$} & \multicolumn{2}{|c|}{$\mathrm{K} 2$} & \multicolumn{2}{|c|}{$\mathrm{K} 1$} & \multicolumn{2}{|c|}{$\mathrm{O} 1$} & \multicolumn{2}{|c|}{$\mathrm{P} 1$} & \multicolumn{2}{|c|}{ M4 } \\
\hline & & $m$ & $o$ & $m$ & $o$ & $m$ & $o$ & $m$ & $o$ & $m$ & $O$ & $m$ & $o$ & $m$ & $o$ & $m$ & $o$ \\
\hline 1 & Milazzo & 12.7 & 12.1 & 5.0 & 4.7 & 2.7 & - & 1.6 & 1.3 & 3.6 & 3.2 & 1.2 & 0.9 & 1.0 & 1.1 & 0.0 & - \\
\hline 2 & Lipari & 12.6 & 12.1 & 4.9 & 4.9 & 2.6 & - & 1.6 & 1.3 & 3.5 & 2.7 & 1.2 & 0.9 & 1.0 & 0.9 & 0.0 & - \\
\hline 3 & Tropea & 13.5 & 14.6 & 5.0 & 5.2 & 2.6 & - & 1.6 & 1.4 & 3.8 & 4.1 & 1.3 & 1.0 & 1.1 & 1.4 & 0.0 & - \\
\hline 4 & Faro & 7.4 & 5.5 & 2.8 & 3.1 & 1.6 & - & 0.9 & 0.8 & 2.3 & 2.3 & 0.7 & 1.0 & 0.6 & 0.8 & 2.4 & - \\
\hline 5 & P.ta Pezzo & 2.5 & 3.3 & 1.4 & 1.3 & 0.6 & - & 0.4 & 0.3 & 1.5 & 1.2 & 1.0 & 0.2 & 0.5 & 0.4 & 1.2 & 1.9 \\
\hline 6 & Reggio C. & 4.5 & 6.2 & 2.6 & 3.0 & 0.8 & - & 0.8 & 0.8 & 1.7 & 1.6 & 1.0 & 0.8 & 0.5 & 0.6 & 0.1 & - \\
\hline 7 & Ganzirri & 4.4 & 3.2 & 1.7 & 1.6 & 1.0 & - & 0.5 & - & 1.5 & 1.4 & 0.5 & 0.5 & 0.4 & - & 0.5 & - \\
\hline 8 & Scylla & 10.1 & 10.2 & 3.8 & 3.2 & 2.2 & - & 1.2 & - & 2.9 & 2.8 & 1.1 & 0.9 & 0.8 & - & 0.1 & - \\
\hline 9 & V.S. Giovanni & 3.1 & 0.9 & 0.7 & 0.8 & 0.8 & - & 0.2 & - & 1.2 & 0.9 & 0.9 & 1.6 & 0.4 & - & 2.7 & - \\
\hline \multirow[t]{2}{*}{10} & Messina & 2.0 & 5.3 & 1.5 & 2.8 & 0.3 & - & 0.5 & - & 0.7 & 0.9 & 0.7 & 0.9 & 0.3 & - & 0.7 & - \\
\hline & & \multicolumn{16}{|c|}{ PHASE (deg) } \\
\hline 1 & Milazzo & 221 & 262 & 287 & 287 & 330 & - & 346 & 287 & 171 & 222 & 93 & 126 & 251 & 222 & 125 & - \\
\hline 2 & Lipari & 220 & 258 & 286 & 286 & 329 & - & 346 & 286 & 172 & 212 & 91 & 162 & 252 & 212 & 51 & - \\
\hline 3 & Tropea & 218 & 274 & 283 & 296 & 327 & - & 349 & 296 & 168 & 219 & 95 & 160 & 247 & 219 & 329 & - \\
\hline 4 & Faro & 227 & 269 & 298 & 314 & 333 & - & 335 & 314 & 183 & 232 & 88 & 251 & 262 & 232 & 171 & - \\
\hline 5 & P.ta Pezzo & 92 & 116 & 119 & 104 & 222 & - & 167 & 104 & 54 & 48 & 20 & - & 131 & 48 & 181 & 72 \\
\hline 6 & Reggio C. & 49 & 95 & 97 & 100 & 176 & - & 179 & 100 & 25 & 57 & 6 & 50 & 108 & 57 & 357 & - \\
\hline 7 & Ganzirri & 235 & 316 & 317 & 354 & 337 & - & 318 & - & 193 & 242 & 75 & 214 & 271 & - & 170 & - \\
\hline 8 & Scylla & 215 & 271 & 281 & 295 & 324 & - & 352 & - & 163 & 220 & 81 & 136 & 243 & - & 167 & - \\
\hline 9 & V. S. Giovanni & 193 & 143 & 265 & 137 & 299 & - & 8 & - & 192 & 236 & 43 & 235 & 198 & - & 179 & - \\
\hline 10 & Messina & 36 & 31 & 83 & 98 & 182 & - & 193 & - & 220 & 290 & 14 & 65 & 110 & - & 24 & - \\
\hline
\end{tabular}

tend to decrease from value around $11 \mathrm{~cm}$ outside the Strait to values lower than $5 \mathrm{~cm}$ inside. This behaviour was similarly described by many authors (Massi et al., 1979; Brandolini et al., 1980; Androsov et al., 2002a), confirming the accuracy of the model results in reproducing the main semidiurnal features of the tidal dynamic in the MS.

Considering the main diurnal K1, the RMSE between the observed and computed amplitudes is about $0.3 \mathrm{~cm}$ with values varying between 0.1 and $0.8 \mathrm{~cm}$. The phases also agree with observations with average discrepancies between observed and computed values around $40^{\circ}$. Similarly, for the main semi-diurnal, the tidal amplitudes of the $\mathrm{K} 1$ also generally decrease inside the Strait even when no rotation of the tidal ellipses was found.

For the main compound tide, M4-wave, the experimental dataset was incomplete, with observations available only for station 5 (Punta Pezzo) on the eastern side of the MS. For this station, the computed amplitude is in line with observations with an estimated discrepancy less than $1 \mathrm{~cm}$. Even if not quantifiable by direct comparison with experimental data, the computed M4 amplitudes vary inside the MS following the same features described by Androsov et al. (2002a), with higher values in proximity of the sill on the eastern side of the MS (stations 9 and 5) and in proximity of Capo Peloro (sta- tion 4) on the western side of the MS. On average, considering the whole set of stations and tidal components, the model results reproduced the observed amplitudes with a RMSE of $0.78 \mathrm{~cm}$, which is fair and acceptable for this type of analysis.

The water circulation induced by the tides in the Strait develops mainly along the main axis of the channel, with a northward flow during the flood and southward flow during the ebb phase. Figure 2 shows the vertically averaged water current fields computed at the maximum flow during both flood (Fig. 2a) and ebb phases (Fig. 2b) of a spring tidal cycle. Numerical results evidenced that, for the sill area, the ebb flow (southward) is generally more intense than the flood flow (northward). Along the $\mathrm{C}-\mathrm{D}$ sections the maximum current speed computed during the spring tidal cycle was about $2.4 \mathrm{~m} \mathrm{~s}^{-1}$ during the ebb and about $2.1 \mathrm{~m} \mathrm{~s}^{-1}$ during the flood flow. Similar features were observed and reported by many authors (Massi et al., 1979; Bignami and Sallusti, 1990; Androsov et al., 2002a). In both phases, the speed variability is high and is modulated by the presence of the sill, which determines an increase of the flow in both directions, with maximum values always found at the eastern side of the Strait, at stations 5 and 9 (Punta Pezzo and Villa San Giovanni).

Water fluxes computed through the sections C-D from the TDO scenario predicted maximum flux values of about 

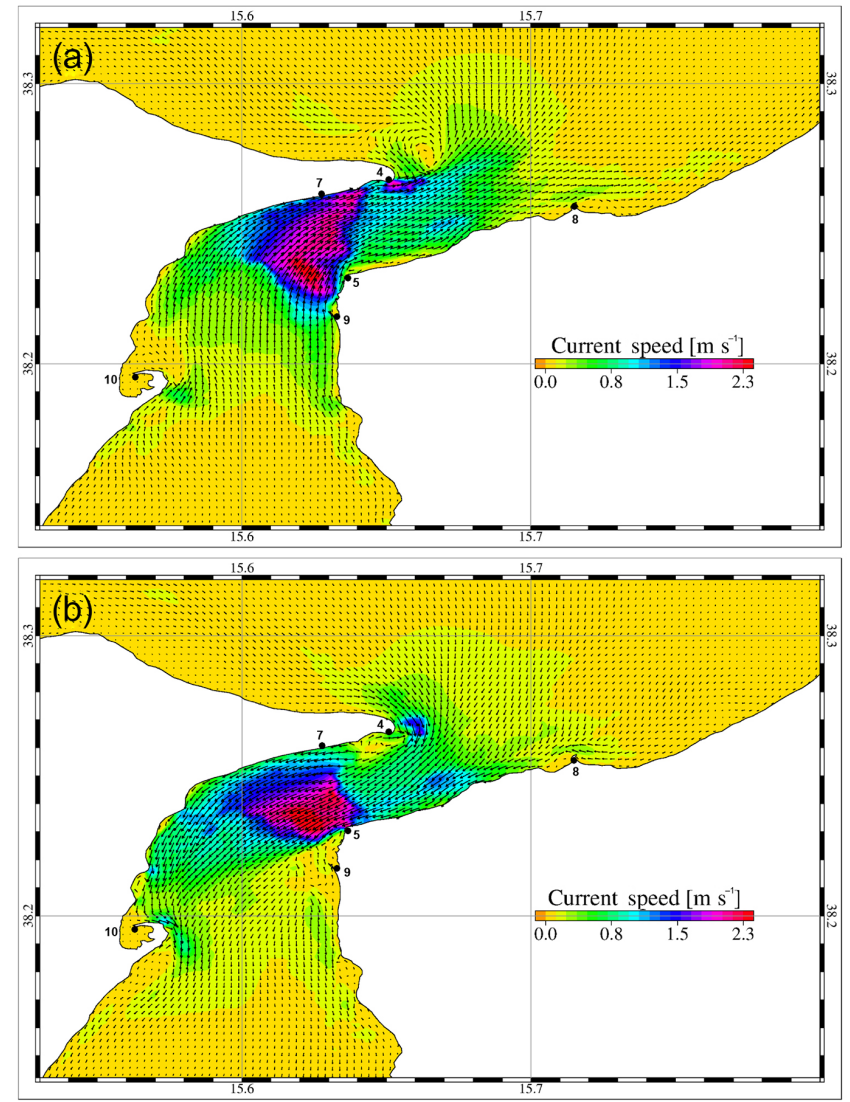

Figure 2. Vertically averaged water currents fields computed at the maximum flow during ebb phase (a) and flood phase (b) of spring tides.

$0.4 \mathrm{~Sv}$ in spring tides during ebb flows. On average, the ebb (southward) and the flood fluxes (northward) were about $0.1 \mathrm{~Sv}$ with differences between the two tidal phases of about $0.01 \mathrm{~Sv}$ and a dominance of southward flows.

During maximum inflow and outflow, advective eddies are generated at the lee side of the main capes. In particular, during the ebb phase (Fig. 2b) an inertial cyclonic feature is generated south of Punta Pezzo (station 5), whereas anticyclonic eddies are produced at the southern side of Capo Peloro in proximity of Ganzirri and Faro (stations 4 and 7) and south of Messina harbour (station 10). Contrarily, during the maximum flood flow (Fig. 2a) a small cyclonic eddy is generated north of Punta Pezzo on the Calabria side, whereas an intense anticyclonic eddy is formed outside of the strait by the intense outflow north of Capo Peloro (station 4). Similar inertial features were described by Cescon et al. (1997), which measured a strong inertial anticlockwise eddies south of Punta Pezzo, at station 5, migrating from the coast to the inner Strait during the ebb flow (see Fig. 2 in Cescon et al., 1997).

These features were not described by previous modelling works as in Androsov et al. (2002a), whose results high-
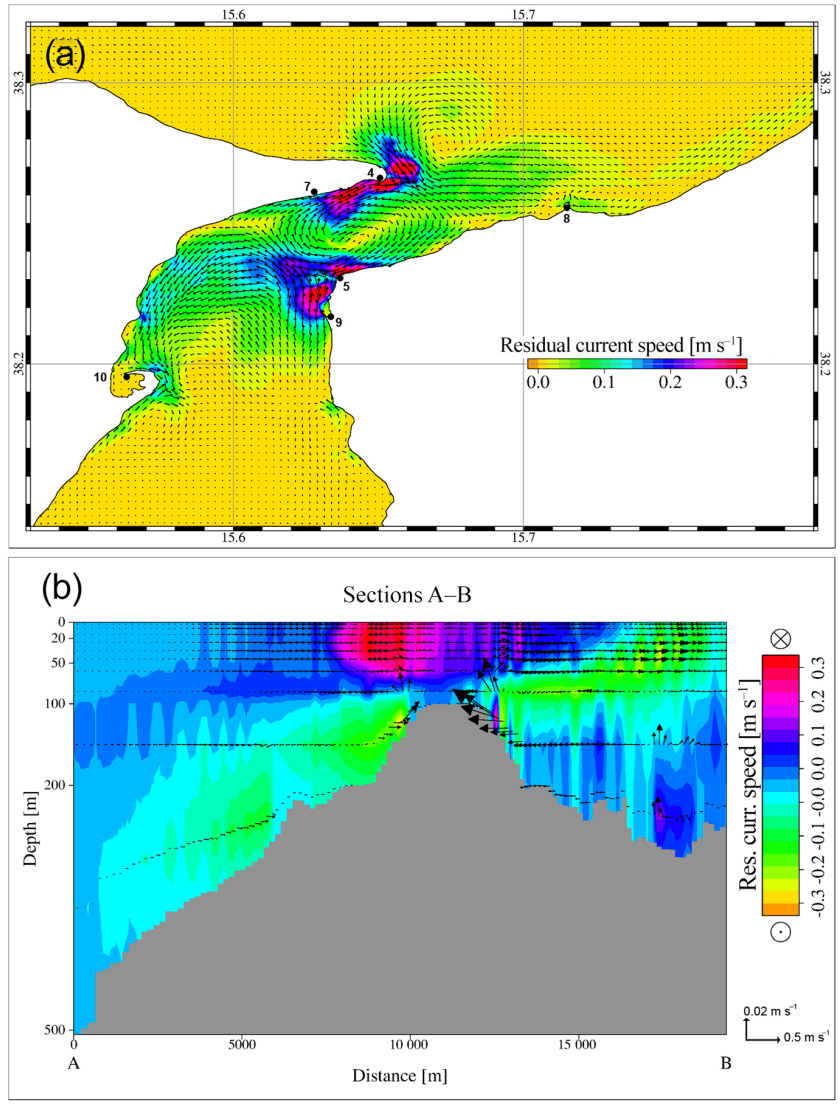

Figure 3. Vertically averaged residual circulation induced by tides in MS (a) and residual flow across (colour bar) and along (vectors) sections A-B (b).

lighted only the flow vorticity generated by the bending of the Strait (see Fig. 12 in Androsov et al., 2002a). In that case, in fact, the low model spatial resolution was not adequate to solve the quasi-inertial features generated by the flow-morphology interactions.

During the slack phases at maximum and minimum tides the circulation pattern is less homogeneous and complicated flow geometries arise from the interaction between the outflowing and the in-flowing water masses.

The aforementioned advective features are the main factors influencing the residual tidal flow inside the Strait. In Fig. 3a the Eulerian residual current field computed for the whole set of simulated synodic months and vertically averaged is reported for the MS area.

The intensities of the residual speeds are not homogeneous inside the MS, with values ranging between a few $\mathrm{cm} \mathrm{s}^{-1}$ up to $0.6 \mathrm{~m} \mathrm{~s}^{-1}$ in proximity of the main capes (Peloro Cape and P.ta Pezzo, stations 4 and 9) and generally around $0.2-$ $0.3 \mathrm{~m} \mathrm{~s}^{-1}$. The computed residual speeds are in line with values found in Androsov et al. (2002a), who found higher values around $0.2 \mathrm{~m} \mathrm{~s}^{-1}$ in the middle of the sill and few $\mathrm{cm} \mathrm{s}^{-1}$ for the deeper part of the Strait. 

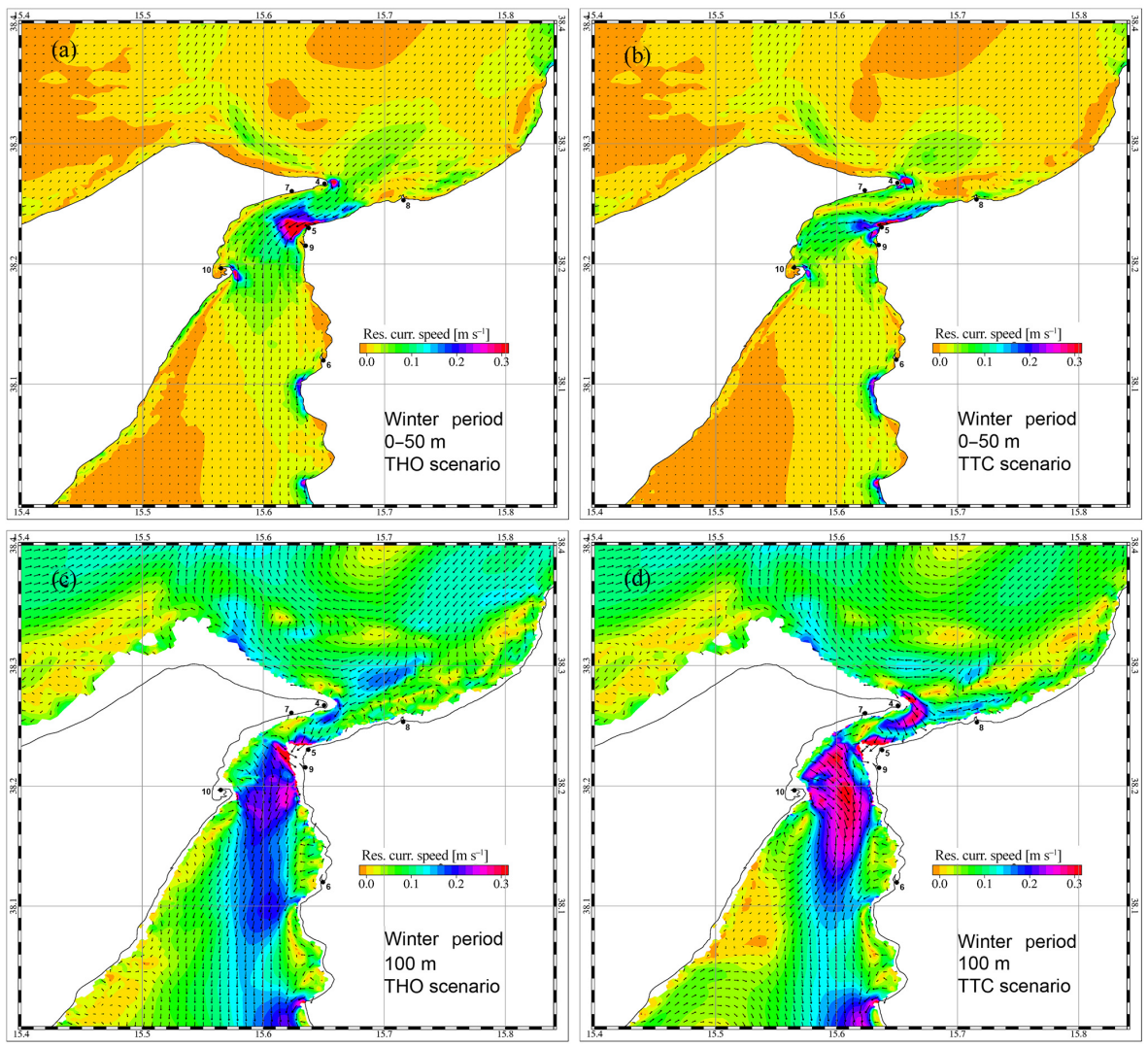

Figure 4. Computed winter residual current field from the THO scenarios results (a and $\mathbf{c})$ and from the TTC scenario results (b and d). Upper panels refer to average residual velocities computed between 0 and $50 \mathrm{~m}(\mathbf{a}$ and $\mathbf{b})$. Bottom panels refer to residual velocities at $100 \mathrm{~m}$ depth (c and d).

Among the presence of the several cyclonic and anticyclonic structures there is also evidence of a fixed circulation pattern which transfers water masses from the Tyrrhenian Sea along the Calabrian coast to the Sicilian coast in proximity of the sill and then southward to the Western Ionian Sea. This was also found in Androsov et al. (2002a) and validated through empirical observations by Mosetti (1988).

Figure $3 \mathrm{~b}$ shows the vertical distribution of the residual circulation along the sections A-B as computed for each model layer. The residual flow is not vertically homogeneous with differences in both direction and intensity. Two main cells, converging in proximity of the sill with an upward flow on both Tyrrhenian and Ionian side, dominate the velocity components of the residual currents along the section. In particular, while the northern cell is continuous, connecting the outer deep layers to the inner surface layers, the southern cell is incomplete and characterized by the presence of convergence zone in the surface layers close to the sill. The component of the residual flow orthogonal to the section is characterized by the presence of an inversion of the current direction between the surface layers and the bottom layers on both side of the sill. The highest residual speeds are found within the top $50 \mathrm{~m}$ depth. The intertidal variability of the residual circulation is generally low with an average standard deviation of the residual current intensity of about $0.05 \mathrm{~m} \mathrm{~s}^{-1}$.

\subsection{The role of tides in modulating the MS general circulation}

The dominant role of tidal forcing in both ruling the exchanges between the two subbasins and modulating the hydrodynamics inside the MS was evidenced by the TDO scenario results.

The quantification of the tidal contribution to the general circulation both inside and outside the Strait was investigated by comparing the THO (without tidal forcing) and the TTC (with tidal forcing) scenario results. In both scenarios the seasonal variations of temperature $(T)$, salinity $(S)$ and velocity fields in the area were reproduced. Simulations results were analysed for typical winter and summer conditions in order to investigate the seasonal variability of the variables of interest.

The comparison was carried out considering the water circulation and the fluxes through the Strait, the $T$ and $S$ distribution and finally the transport dynamics as reproduced by the two scenarios. 

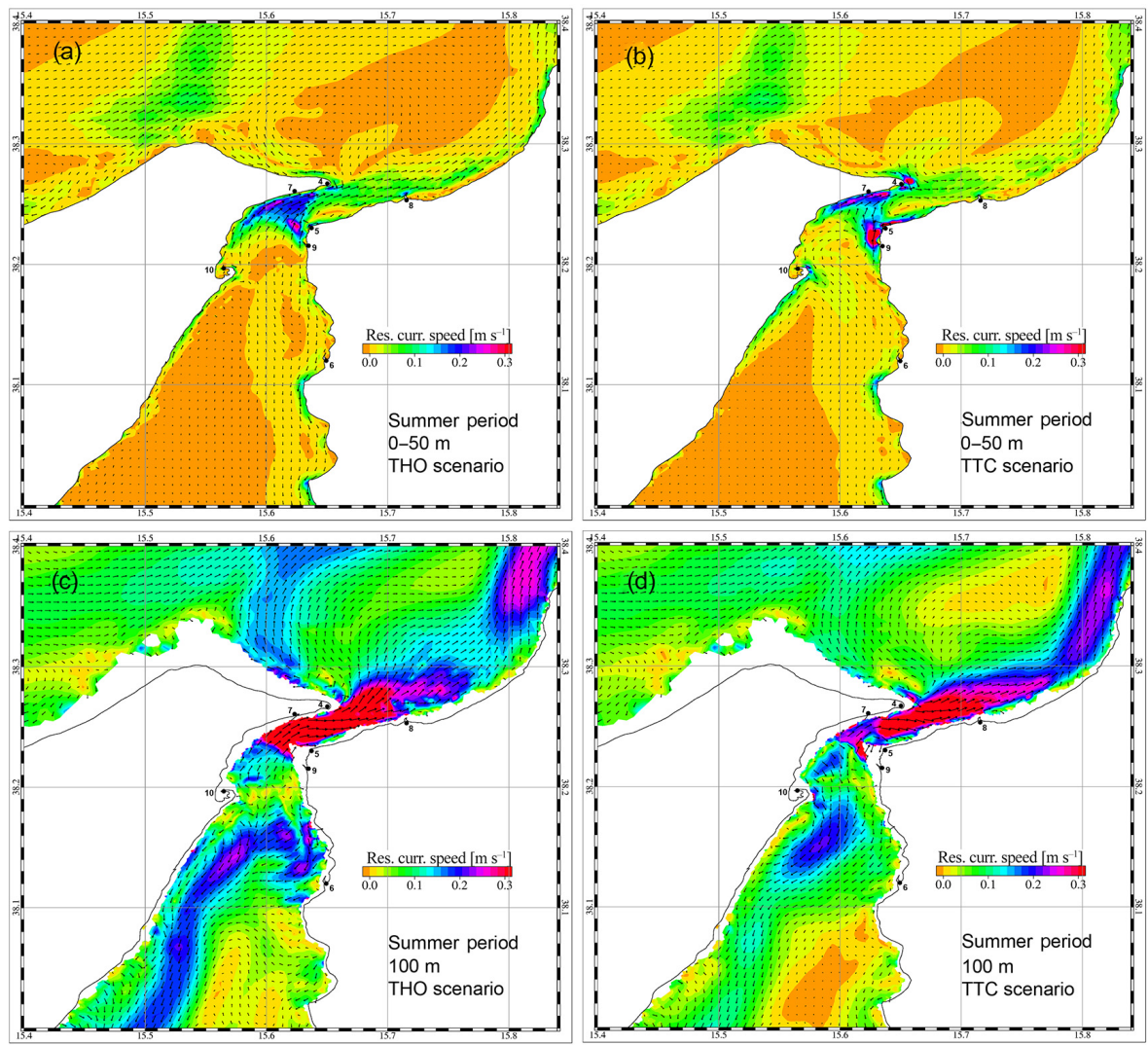

Figure 5. Computed summer residual current field from the THO scenarios results (a and c) and from the TTC scenario results (b and d). Upper panels refer to average residual velocities computed between 0 and $50 \mathrm{~m}$ (a and $\mathbf{b})$. Bottom panels refer to residual velocities at $100 \mathrm{~m}$ depth (c and $\mathbf{d})$.

\subsubsection{Water circulation}

The comparison between the instantaneous current fields obtained from the THO and TTC scenarios is trivial. In fact, the differences between the speeds intensities in the two cases were higher than a magnitude order. Speed values of some $\mathrm{m} \mathrm{s}^{-1}$ were obtained when including the tidal forcing, whereas a few $\mathrm{cm} \mathrm{s}^{-1}$ were computed when excluding the tides. Therefore, the influence of the tides on the longterm circulation patterns was investigated by computing and analysing the residual flow in the two scenarios.

In Figs. 4 and 5 the residual currents computed for winter and summer seasons as the algebraic averages of the threedimensional hourly current speeds obtained for winter (January, February and March) and summer months (July, August and September) during the 2 years of simulation are reported for both scenarios. Upper panels ( $\mathrm{a}$ and $\mathrm{b}$ in Figs. 4 and 5) refer to the residual circulation obtained as the vertical averages of the residual velocities computed between the surface and the $50 \mathrm{~m}$ depth layer. Bottom panels (c and d in Figs. 4 and 5) refer to the residual field computed at the $100 \mathrm{~m}$ depth layer, which include the deepest part of the MS sill and where Tyrrhenian and Ionian deeper waters signals can be detected.
Left (b and d in Figs. 4 and 5) and right (a and c in Figs. 4 and 5) panels depict the results obtained without and with the tidal contribution respectively.

Inside the MS, during the winter period, the wind and thermohaline forcings only (THO scenario) generate a residual circulation mainly homogeneous in space and directed southward with average speeds around $0.1 \mathrm{~m} \mathrm{~s}^{-1}$ (Fig. 4a). Local intensifications are found in proximity of the main capes and on the eastern side of the sill where a residual speed up to $0.6 \mathrm{~m} \mathrm{~s}^{-1}$ is detected at the surface layers. At $100 \mathrm{~m}$ depth (Fig. 4c), the residual current field is generally more intense than at the surface, with average values higher than $0.2 \mathrm{~m} \mathrm{~s}^{-1}$ and peak values of $0.68 \mathrm{~m} \mathrm{~s}^{-1}$. The deeper residual flow is also directed southward with a more homogeneous pattern found in the southern part of the MS.

Considering the TTC scenario results, the surface residual circulation obtained for winter months (Fig. 4b) is strongly modulated by the residual tidal current field (Fig. 3a) as evidenced by the presence of anticyclonic and cyclonic gyres within the Strait. Similar values, around $0.6 \mathrm{~m} \mathrm{~s}^{-1}$, were found for the surface peak speeds. Contrary, in the deeper layers (Fig. 4d), the action of tidal forcing, while preserving the current pattern generated by the wind and heat fluxes, 
(a)

WATER FLUXES THROUGH THE MESSINA STRAIT - sec. CD - winter period

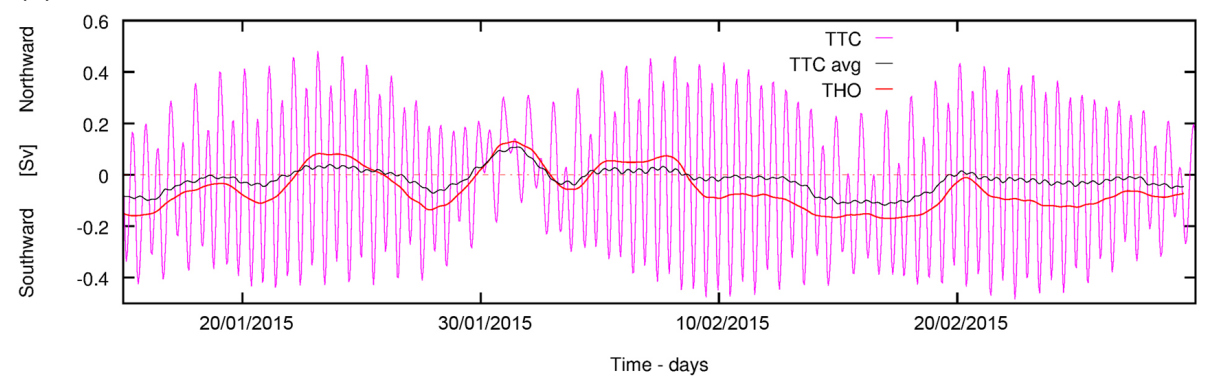

(b)

WATER FLUXES THROUGH THE MESSINA STRAIT - sec. CD - winter period

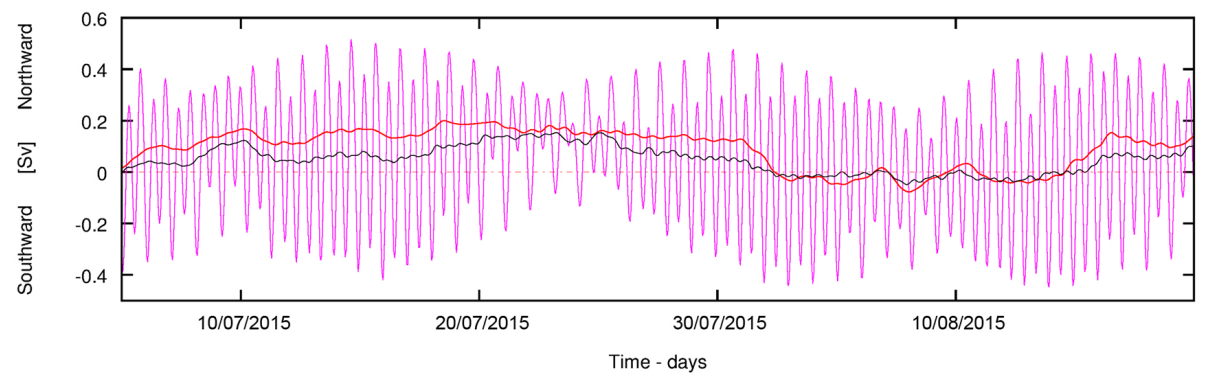

Figure 6. Water fluxes through sections C-D computed for 45 days during winter (a) and summer (b) periods from THO scenario results (red line) and from TTC scenario results (blue line for hourly data, black line for daily data); units are expressed in Sv, with negative values indicating southward flux (ebb flow) and positive a northward flux (flood flow).

tends to favour a general increment of the average residual speed intensities, which, in this case, are higher than $0.3 \mathrm{~m} \mathrm{~s}^{-1}$. Outside the MS, both on the Tyrrhenian and Ionian sides, the action of the tides tends to reduce the residual speeds intensities and to increase the number of small-scale gyres generated at the MS mouths. As expected, the differences in the open ocean residual fields due to the tidal contribution are generally small and tend to be reduced with the distance from the MS.

During the summer period, the wind-induced and thermohaline residual circulation (THO scenario) at the surface (Fig. 5a) is less intense, with peak speeds around $0.3 \mathrm{~m} \mathrm{~s}^{-1}$ and, contrary to winter period, is directed northward in the northern part of the Strait and southward in the southern part. The same pattern is found at the deeper depths where a stronger residual flow, up to $0.7 \mathrm{~m} \mathrm{~s}^{-1}$, rising at the sill moves northward into the Tyrrhenian Sea and, bending eastward, generates a coastal current on the Calabria side (Fig. 5c). In the southern opening of the MS, the southward flow is less intense, around $0.2 \mathrm{~m} \mathrm{~s}^{-1}$, and mainly confined to the western side of the Strait. In both, surface and deeper layers, a divergence area is detected south of the sill in front of the Messina harbour (station 10).

As for the winter period, when tidal forcing is included (TTC scenario), the surface residual current pattern inside the MS (Fig. 5b) differs mainly for the presence of anticyclonic and cyclonic structures generated by the residual tidal flow. A general reduction of the residual current speeds is recorded at both surface and deep layers and both inside and outside the MS. In this case, the tidal action, while preserving the general pattern, tends to modify the two main residual flows, the northward and southward one, both inside and outside the MS. This is particularly evident at the $100 \mathrm{~m}$ depth layer outside the MS in the Tyrrhenian Sea (Fig. 5d), where the coastal current along the Calabria side is stronger and sharper than the one obtained from THO scenario results (Fig. 5c). In contrast, in the Ionian waters, the tidal forcing tends to disrupt the southward coastal flow by reducing its maximum speed and by smoothing the horizontal velocity gradients. Finally, the tidal action reduces the extension of the divergence areas inside the MS at both surface and deeper depths.

Water fluxes through sections C-D were computed during both winter and summer months from the THO and TTC scenarios results. The winter period included January, February and March, whereas the summer period included the months of July, August and September of both simulated years. As an example, in Fig. 6 the time series of the computed fluxes are reported, for reason of clarity, only for 45 days during both summer and winter 2015 and for the THO and TTC scenarios.

The magnitude of the computed fluxes differs between the two scenarios, with peak values higher than $0.4 \mathrm{~Sv}$ obtained when including the tides (blue lines in Fig. 6a and b) and values always less than $0.2 \mathrm{~Sv}$ when not (red lines in Fig. 6a and $b$ ). As expected, the differences between the TTC and the THO net fluxes are always different from 0 . This is evident when considering the $24 \mathrm{~h}$ mobile averages computed from the TTC results (black line in Fig. 6a and b) where values, 
even when generally following the trend, are always differing from the computed THO fluxes. TTC and THO scenarios differ mainly for the net flux budget between the inflows and the outflows.

In Table 3 the average positive, negative and net fluxes computed during the winter and summer periods are reported for both scenarios. Also in this case, the differences between the THO and TTC results are found for both the northward and the southward fluxes, with TTC average values always greater than THO one, with values ranging between 0.084 and $0.04 \mathrm{~Sv}$. This is particularly clear for the winter period when the less intense density gradients, leading to a lower contribution to the general circulation, tend to increase the differences between the two scenarios.

From both scenarios, the computed net flux is negative in winter (indicating a prevailing southward average flow) and positive in summer (indicating a prevailing northward average flow). The tidal forcing tends to smooth these discrepancies (TTC-THO in Table 3) with a reduction of $0.042 \mathrm{~Sv}$ to the net southward flux in winter and a reduction of $0.039 \mathrm{~Sv}$ to the net northward flux in summer.

\subsubsection{Thermohaline features}

The temporal and spatial variability of the water salinity and temperature was computed for both the TTC and THO scenarios and for the whole considered period. Summer and winter thermohaline properties of the water masses were also analysed and compared to each other.

From the TTC scenario results, the vertically averaged salinity in the MS area varied between 37.7 PSU, for the Tyrrhenian waters in the northern part, and 38.6 PSU, for the Ionian waters in the southern side, with average differences between winter and summer periods of about 0.5 PSU. The variation of the salinity fields due to the tidal contribution in the MS is, on average, less than 0.2 PSU with a general increment of salty water during summer and a decrease during the winter periods.

Figure 7 shows the winter and summer average salinity distributions computed from the THO and the TTC scenario results along sections A-B. In the winter period (Fig. 7a and b), due to the negative net flux budget across the Strait which indicates a prevailing southward flow, the saltier Ionian deep waters are mainly confined to the southern side of the sill. The action of tides, favouring the exchanges at the interface, tends to increase the outflow of saltier Ionian deep waters on the northern side of the Strait (Fig. 7b). This is confirmed by the computation of the average net salt fluxes through sections C-D (Table 3) that indicates a general decrease of the southward flux component, estimated around $1.6 \mathrm{~Sv}$, when considering the tidal contribution. The differences in the vertical structures between the two scenarios are mainly due to the tidal residual current field, which is characterized by a convergence zone in proximity of the sill (Fig. 3b) that tends to foster the rising of the deeper and saltier waters.
In summer period, the average northward net flux (Table 3) causes the partial overflow of the Ionian lower surface waters across the sill into the northern side of the MS. While tidal exchanges generally tend to counteract this process, as confirmed by the negative differences of $-0.039 \mathrm{~Sv}$ between the net fluxes in the two scenarios (Table 3), the tidal residual flow tends to increase the salinity on the northern side of the sill. This is confirmed by the ratio between the TTC and THO net fluxes which, in the case of water fluxes, is around 0.56 and, in the case of salt fluxes, is slightly higher up to 0.61 (see Table 3, $2.051 \mathrm{~Sv}$ in the TTC scenario versus $3.355 \mathrm{~Sv}$ obtained for the THO scenario), therefore indicating that the horizontal flow is not the only factor regulating the salt budget through the section.

During winter, the water $T$ in the area is mainly homogeneous, ranging between 14 and $17^{\circ} \mathrm{C}$ with average values around $14.5^{\circ} \mathrm{C}$ and small variations in the vertical due to the absence of thermal stratification and to the strong mixing. During this period, the effects of the tidal action in changing the $T$ fields are negligible, with differences between the THO and TTC scenarios around 0.1 and $0.2^{\circ} \mathrm{C}$.

During summer, due to the strong heat fluxes and the intense large-scale thermohaline circulation, the $T$ distribution in the area is heterogeneous both horizontally and vertically. In Fig. 8a the average surface $T$ computed from the TTC scenario results is reported for the extended domain comprising the MS and part of the two subbasins. The values vary between 19 and $26^{\circ} \mathrm{C}$ with the lowest $T$ found in the MS, south of the sill, and higher values found in the shallow water banks on both the Tyrrhenian and Ionian costal areas. The computed $T$ distribution is in line with measurements carried out by Cescon et al. (1997), who individuated cores of cold waters inside the MS both south of the sill and south of the Messina harbour on the Sicilian side of the Strait (see Fig. 7 in Cescon et al, 1997). During the summer period, the tides, modifying the instantaneous and the residual flow pattern and increasing the mixing processes at the interfaces, cover an important role in shaping the surface $T$ fields in the area.

In Fig. 8b the differences between the average surface $T$ computed from TTC and THO scenarios results are reported. For the offshore fields, in both the Tyrrhenian and Ionian Sea, where the $T$ variability is mainly ruled by the largescale thermohaline circulations, the changes due to the tidal action are negligible. However, significant differences due to the tidal action are found both inside, with a decrease of $T$ up to $1^{\circ} \mathrm{C}$, and outside the Strait along the coastal areas, with a general increment of the $T$, varying between 0.3 and $0.7^{\circ} \mathrm{C}$.

Inside the MS, the tides tend to reduce the surface $T$ in proximity of the sill with the consequent increase of the model prediction accuracy, as suggested by the comparison with the experimental dataset obtained by Cescon et al (1997). In fact, differently from Cescon et al. (1997), the model results obtained from the THO scenario (without the tidal action) foresee the minimum $T$ areas in front of Reggio 

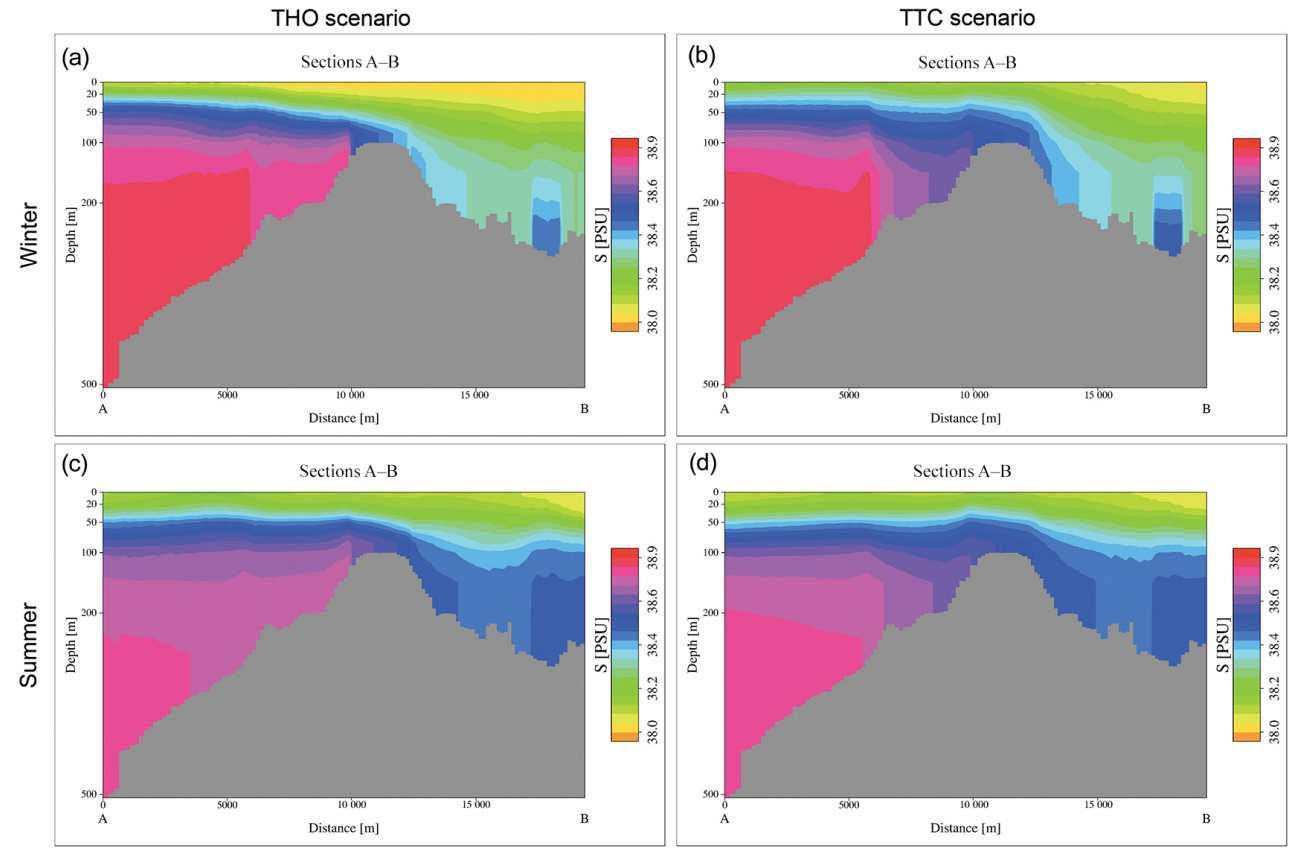

Figure 7. Vertical distribution of the average water salinity expressed in PSU computed along the sections A-B from THO (a and c) and TTC scenario results (b and $\mathbf{d}$ ) for winter (a and $\mathbf{b}$ ) and summer periods (panels c and).
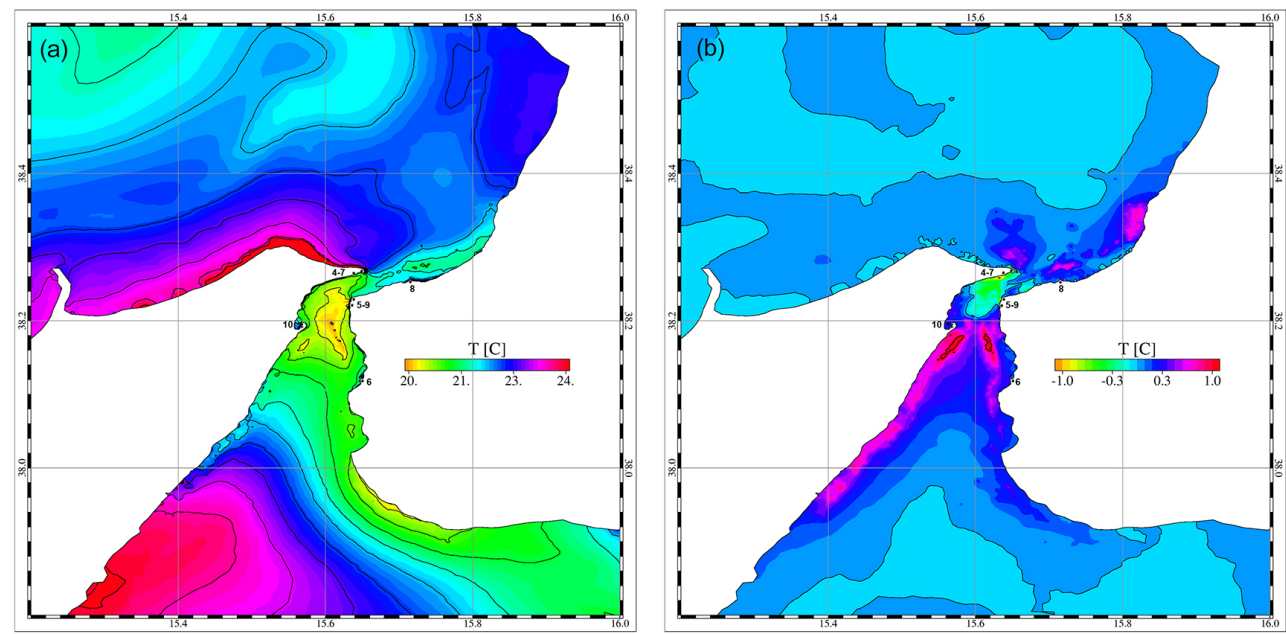

Figure 8. Surface water temperature computed during the summer period: average values from the TTC simulation results (a) and differences with respect to the THO scenarios results (b).

Calabria (station 11) and south of the Strait, whose patterns are not found in the experimental dataset.

Off the northern mouth, in the Tyrrhenian Sea, the tides induce an average increase of $T$, up to $0.8^{\circ} \mathrm{C}$, of the surface waters carried by the northward coastal current along the eastern side of the subbasin. Similarly, in the Ionian side of the Strait, the $T$ computed from TTC scenario are generally higher than ones from the THO scenario, with increments ranging between 0.3 up to $1.4{ }^{\circ} \mathrm{C}$ and the highest differences found along both the Sicilian and Calabria coasts.
The vertical distributions of the average summer $T$ along the sections A-B (Fig. 9a and b), as computed from both scenario results, highlight the pronounced thermal stratification due to the intense heat fluxes. $T$ values range between $14^{\circ} \mathrm{C}$ for the lower surface Tyrrhenian and Ionian waters and $22^{\circ} \mathrm{C}$ for the surface waters. Similarly to the salinity fields (Fig. 7d), in proximity of the sill, the tides (Fig. 9b) favour the uplift of the isotherms with a consequent general reduction of the $T$ along the water column. A general decrease in $T$ is also found for the whole northern side of the section, 

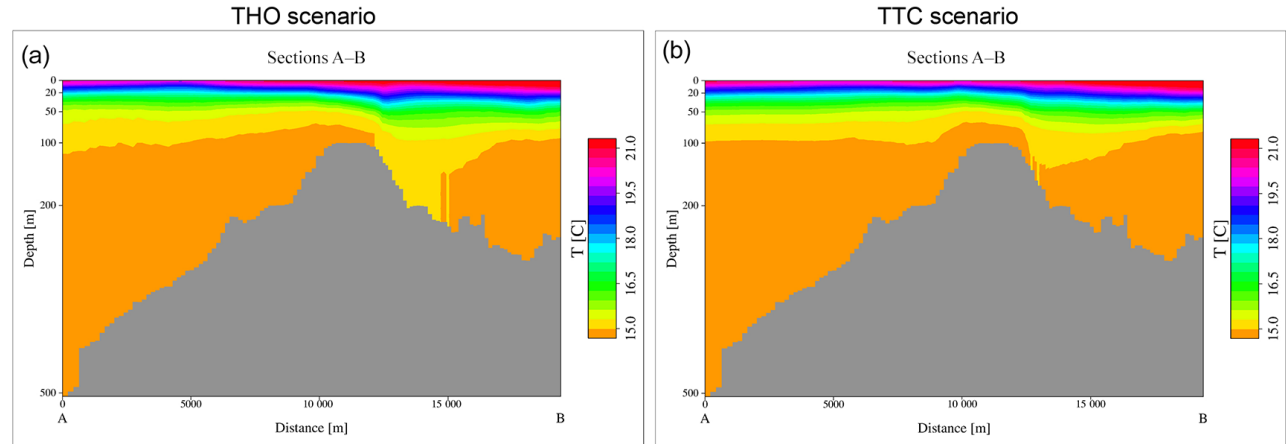

Figure 9. Summer average water temperature along sections A-B computed from THO and TTC scenarios (b and d).

Table 3. Water, salt and heat fluxes through sections C-D computed for winter and summer periods from THO and TTC scenario results and differences (TTC-THO). Water and salt fluxes are expressed in $\mathrm{Sv}$, heat fluxes in $10^{7} \mathrm{~W}$. The south flux and north flux are considered as absolute values. The net flux $(\mathrm{N}-\mathrm{S})$ values are obtained as the differences between north flux and south flux values. Positive values indicate a northward net flux; negative values indicate a southward net flux.

\begin{tabular}{llrrr}
\hline \multicolumn{5}{c}{ Water flux through sections C-D (units expressed in Sv) } \\
Season & Scenario & Net flux (N-S) & North flux & South flux \\
\hline \multirow{3}{*}{ Winter } & TTC & -0.022 & 0.097 & 0.120 \\
& THO & -0.065 & 0.014 & 0.080 \\
& TTC-THO & 0.042 & 0.082 & 0.040 \\
\hline \multirow{3}{*}{ Summer } & TTC & 0.052 & 0.131 & 0.078 \\
& THO & 0.092 & 0.101 & 0.008 \\
& TTC-THO & -0.039 & 0.029 & 0.069 \\
\hline
\end{tabular}

\begin{tabular}{llrrr}
\hline \multirow{5}{*}{ Season } & \multicolumn{4}{c}{ flux through sections C-D (units expressed in Sv) } \\
& Scenario & Net flux (N-S) & North flux & South flux \\
\hline \multirow{4}{*}{ Winter } & TTC & -0.846 & 3.755 & 4.601 \\
& THO & -2.493 & 0.565 & 3.058 \\
& TTC-THO & 1.646 & 3.189 & 1.542 \\
\hline \multirow{4}{*}{ Summer } & TTC & 2.051 & 5.044 & 2.992 \\
& THO & 3.355 & 3.892 & 0.337 \\
& TTC-THO & -1.503 & 1.151 & 2.655 \\
\hline
\end{tabular}

\begin{tabular}{llrrr}
\hline \multicolumn{5}{c}{ Heat flux through sections C-D (units expressed in $10^{7} \mathrm{~W}$ ) } \\
Season & Scenario & Net flux (N-S) & North flux & South flux \\
\hline \multirow{4}{*}{ Winter } & TTC & -2.775 & 11.767 & 14.543 \\
& THO & -7.927 & 1.770 & 9.697 \\
& TTC-THO & 5.151 & 9.997 & 4.845 \\
\hline \multirow{3}{*}{ Summer } & TTC & 6.387 & 15.887 & 9.500 \\
& THO & 11.195 & 12.278 & 1.082 \\
& TTC-THO & -4.807 & 3.609 & 8.417 \\
\hline
\end{tabular}

especially in the deeper layers where the residual circulation induced by tides favours the displacement of the deeper and colder Tyrrhenian waters toward the surface.

The heat fluxes through sections A-B was computed for both summer and winter periods (see Table 3), revealing in the Tyrrhenian basin an average net heat loss of about $2.7 \times 10^{7} \mathrm{~W}$ during winter and an average heat gain during summer of around $6.4 \times 10^{7} \mathrm{~W}$, as estimated from TTC scenario.

The action of tides tends to reduce the discrepancies between northward and southward flows with a similar contribution found in the analysis of the water fluxes. In fact, the ratios between the TTC and THO net values are about 0.35 for the winter period (see Table $3 ;-2.7 \times 10^{7} \mathrm{~W}$ in the TTC scenario versus $-7.9 \times 10^{7}$ obtained for the THO scenario) and 0.57 for the summer period (see Table 3, $6.3 \times 10^{7}$ in the TTC scenario versus $-11.2 \times 10^{7}$ obtained for the THO scenario), which are similar to the values found for the water net fluxes, with 0.34 and 0.56 respectively, thus indicating the changes in horizontal advection as the main factor ruling the heat balance at the interface.

\subsubsection{Transport processes}

The transport of water masses through the MS is a fundamental process to be investigated in order to understand the importance of this narrow passage on the hydrodynamics of the surrounding open and coastal seas areas.

The effects of tidal action on the exchanges through the MS were evaluated considering its role in changing the dominance of Tyrrhenian and Ionian waters in the Ionian and Tyrrhenian subbasins respectively. Specifically, passive tracers were monthly released with unitary concentration in the southern part of the MS, south of station 10, for tracking Ionian waters, and in the northern part of the basin, north of stations 4 and 8 , for tracking Tyrrhenian waters. The trajectories of both tracers were simulated for the whole considered period in both TTC and THO scenarios. The winter and the summer monthly average distribution of the tracer [C] were then analysed. 

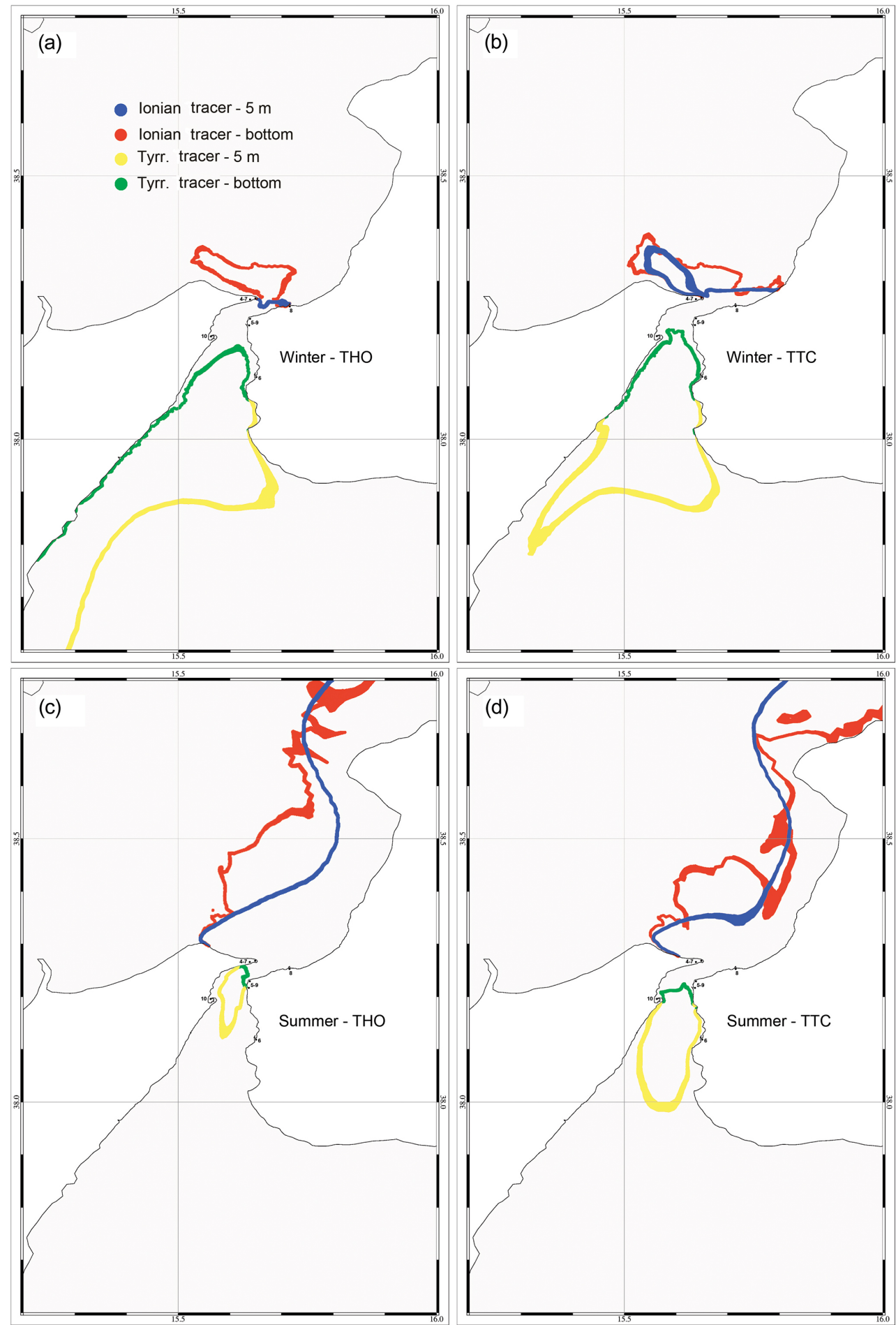

Figure 10. Monthly average distribution of tracers release during winter (upper panels) and summer (lower panels) from THO (left panels) and TTC scenario results (right panels). Coloured areas refer to values with $10 \%$ the initial tracer concentration. Red and blue lines refer to Ionian tracked waters at bottom and surface layers. Green and yellow lines refer to Tyrrhenian tracked bottom and surface layers water.

In Fig. 10, the $0.1[\mathrm{C}]$ contour lines for the surface $(5 \mathrm{~m}$ depth) and bottom layers are reported for both the Tyrrhenian (blue and red lines in Fig. 10) and Ionian tracers (green and yellow lines in Fig. 10) and for winter (Fig. 10a and b) and summer (Fig. 10c and d) as obtained from the THO and TTC scenarios (Fig. 10a and c). 
The $10 \%$ contour lines for both surface and bottom layers indicate that during winter (Fig. 10a and b), the tidal action favours the outflow of Ionian waters into Tyrrhenian Sea and tends to reduce the presence of Tyrrhenian waters into the Ionian Sea. For both tracers, the highest variations between the two scenarios are found in the surface waters. In particular, for the Ionian tracer, the tides increase the surface with an average [C] of about $14 \%$ for surface layer and about the $3 \%$ for bottom layer. Similarly, the reduction of the area with Tyrrhenian tracer [C] greater than $10 \%$ is higher for surface waters, with about the $-40 \%$, and lower for bottom layers, with about the $-10 \%$. For both tracers the maximum differences induced by the tides are confined within the first $200 \mathrm{~m}$, corresponding to the bathymetric threshold imposed by the sill depth.

In contrast, during summer (Fig. 10c and d), the contour lines indicate that tidal forcing generates the outflow of the Tyrrhenian waters into the Ionian Sea and tends to foster the propagation of Ionian waters northward. In particular, for Ionian waters, the reduction of the surface with tracer [C] greater than $10 \%$ was higher in deeper layers, up to $40 \%$ at the $200 \mathrm{~m}$ depths, and lower for surface layers, about $19 \%$ at $5 \mathrm{~m}$ depth. This is in line with the results obtained by the analysis of the residual circulation (Fig. 5b); in fact, the tidal action, while reducing the residual current fields in the area, tends to maintain and intensify the strong coastal current on the eastern side of the basin. This is evidenced by the fact that in the case of tide, even if the $10 \%$ contour lines is less extended, the average tracer [C] in the surface layers of the Calabria coastal areas are always higher than those found in the THO scenario. In contrast, for the Tyrrhenian tracer, the increment of the area with [C] higher than $10 \%$ induced by the tidal action is higher for surface layers, around $35 \%$ at $5 \mathrm{~m}$, and lower for deeper layers, with $5 \%$ at $100 \mathrm{~m}$.

\section{Conclusions}

The focus of this work was the investigation of the effects of the reproduction of the tidal dynamics on modelling the general circulation in the Messina Strait, a narrow passage connecting the Tyrrhenian and the Ionian Sea subbasins in the Western Mediterranean Sea.

The adopted approach highlighted the role of the tides in modulating the local circulation patterns and allowed to quantify the effects of the Strait tidal hydrodynamics on the circulation of the surrounding coastal waters. These aspects are particularly important when dealing with operational oceanography systems designed to provide short-term predictions that, in turn, can be used by other end-user applications such as decision support systems for maritime safety (Mannarini et al., 2016a, b) or simply to provide basic fields for marine forecasting applications.

These operational oceanographic systems are generally characterized by low spatial resolution, on the order of some kilometres, which is too coarse to reproduce the tidal dynamics and the general circulation inside this narrow passage. As a consequence, these systems are also not suitable to make predictions over a large extent of the surrounding open sea areas where the influence of the Strait dynamic was found to be important. For this area, in fact, the correct reproduction of the MS tidal dynamics deeply impacts on the prediction of the instantaneous and residual circulation pattern, the thermohaline properties and transport dynamics.

Considering the exchanges between the two subbasins through the MS, the correct reproduction of the tidal propagation in the Strait can generate changes in water fluxes ranging between $800 \%$, when considering the instantaneous values, and $60 \%$ when estimated from the residual flows.

Although these values slightly influence the overall flux budgets of the two subbasins, the increase in current speeds in the Strait due to tides, as well as the intensification of the interactions between water masses with different thermohaline properties, lead to intense modifications of the current and thermohaline fields in Tyrrhenian, Sicily channel and southern Ionian coastal waters. In fact, considering the Tyrrhenian and Sicily Channel water mass budgets, while the net fluxes through the MS are up to 2 orders of magnitude lower than the monthly average fluxes through the Sardinian and Sicily Straits, with $10^{-2} \mathrm{~Sv}$ (Table 3) and $1 \mathrm{~Sv}$ (Béranger et al., 2005) respectively, the instantaneous fluxes through the MS, with average values up to $10^{-1} \mathrm{~Sv}$ (see Table 3) and maximum values around $0.5 \mathrm{~Sv}$ (Fig. 6), are comparable with the fluxes through the other boundaries (Béranger et al., 2005) and therefore able to influence substantially the thermohaline features of the two subbasins.

This is particularly evident from the water temperature analysis in the outer coastal areas, where a correct reproduction of the MS dynamics led to changes in surface $T$ distribution over an external area of about $1500 \mathrm{~km}^{2}$, extending up to $60 \mathrm{~km}$ from the Strait. Finally, considering potential oil spill or dissolved pollutant contamination, the correct reproduction of the tidal dynamics in the MS-generated substantial differences in the transport patterns in the area. The analysis of transport properties revealed that, on a monthly timescale, the difference in the sea surface area interested by a hypothetical continuous release in the MS is up to $40 \%$ between the two scenarios.

The obtained results confirmed the importance of reproducing correctly the MS dynamics even when focusing on predicting the hydrodynamics of the external sea areas. This is not only the case of Messina Strait and Tyrrhenian and Ionian Sea and Sicily Channel subbasins; in fact, most of the open ocean operational systems applied to areas with complicated geometry, including narrow passages and straits, are not suitable to correctly reproduce the hydrodynamics of coastal waters and consequently their role in influencing the open ocean current pattern. In our study case, the water circulation inside the Strait was particularly important in shaping the outer seas current patterns and thermohaline features. 
Therefore, the use of numerical procedures, including both open ocean and high-resolution coastal hydrodynamic models, is highly suggested even for operational oceanographic systems focused on predicting the open ocean hydrodynamic fields.

Acknowledgements. This research was funded by the project TESSA (Technologies for the Situational Sea Awareness) project funded by the Italian Ministry for Environment.

Edited by: I. Federico

Reviewed by: two anonymous referees

\section{References}

Androsov, A. A., Kagan, B. A., Romanenkov, D. A., and Voltzinger, N. E.: Numerical modelling of barotropic tidal dynamics in the strait of Messina, Adv. Water Resour., 25, 401-415, doi:10.1016/S0309-1708(02)00007-6, 2002a.

Androsov, A. A., Voltzinger, N. E., and Romanenkov, D. A.: Simulation of three-dimensional baroclinic tidal dynamics in the strait of Messina, Atmos. Ocean Phys., 38, 105-118, $2002 \mathrm{~b}$.

Astraldi, M. and Gasparini, G. P.: The seasonal characteristics of the circulation in the Tyrrhenian Sea, In: Seasonal and interannual variability of the western Mediterranean Sea, Coastal and Estuarin Studies Series, AGU, 46, 115-134, 1994.

Bellafiore, D., Umgiesser, G., and Cucco, A.: Modeling the water exchanges between the Venice Lagoon and the Adriatic Sea, Ocean Dynam., 58, 397-413, 2008.

Bellafiore, D., Guarnieri, A., Grilli, F., Penna, P., Bortoluzzi, G., Giglio, F., and Pinardi, N.: Study of the hydrodynamical processes in the Boka Kotorska Bay with a finite element model, Dynam. Atmos. Ocean., 52, 298-321, doi:10.1016/j.dynatmoce.2011.03.005, 2011.

Béranger, K., Mortier, L., and Crépon, M.: Seasonal variability of water transport through the Straits of Gibraltar, Sicily and Corsica, derived from a high-resolution model of the Mediterranean circulation, Prog. Oceanogr., 66, 341-364, doi:10.1016/j.pocean.2004.07.013, 2005.

Blumberg, A. F. and Mellor, G. L.: A description of a three-dimensional coastal ocean circulation model, in: ThreeDimensional Coastal Ocean Models, edited by: N. S. Heaps, Coastal and Estuarine Science, No. 4, American Geophysical Union, Washington D.C., 1-16, 1987.

Bignami, F., and Salusti, E.:Tidal currents and transient phenomena in the Strait of Messina: A review. The Physical Oceanography of Sea Straits, edited by: Pratt, L. J., Kluwer Academic, 95-124, 1990.

Bossolasco, M. and Dagnino, I.: Sulla turbolenza delle correnti marine nello Stretto di Messina, Geofis. Pura Appl., 37, 318-324, 1957.

Bossolasco, M. and Dagnino, I.: La diffusione delle acque ioniche nel Tirreno attraverso lo Stretto di Messina, Geofis. Pura Appl., 44, 318-324, 1959.

Brandolini, M., Franzini, L., and Salusti, E.: On tides in the Strait of Messina, Il Nuovo Cimento, 3, 671-695, 1980.
Brandt, P., Rubino, A., Alpers, W., and Backhaus, J. O.: Internal Waves in the Strait of Messina Studied by a Numerical Model and Synthetic Aperture Radar Images from the ERS 1/2 Satellites, J. Phys. Oceanogr., 27, 648-663, doi:10.1175/15200485(1997)027<0648:IWITSO>2.0.CO;2, 1997.

Brandt, P., Rubino, A., Quadfasel, D., Alpers, W., Sellschopp, J., and Fiekas, H.-V.: Evidence for the Influence of Atlantic-Ionian Stream Fluctuations on the Tidally Induced Internal Dynamics in the Strait of Messina, J. Phys. Oceanogr., 29, 1071-1080, doi:10.1175/1520-0485(1999)029<1071:EFTIOA>2.0.CO;2, 1999.

Burchard, H. and Petersen, O.: Models of turbulence in the marine environment, a comparative study of two-equation turbulence models, J. Marine Syst., 21, 29-53, doi:10.1016/S09247963(99)00004-4, 1999.

Carta, G., D’Epifanio, R., and Monti, S.: Le Correnti di Marea nello Stretto di Messina, Technical Report, Istituto Idrografico della Marina, Genova, 43, 2008.

Cescon, B., Azzaro, F., Creazzo, S., Decembrini, F., and Magazzu, G.: Processes affecting upwelling and primary productivity of the Messina Straits, Bollettino di Geofisica Teorica ed Applicata, 38, 1-2, 1997.

Coiro, D., Troise, G., Ciuffardi, T., and Sannino, G.: Tidal current energy resource assessment: The Strait of Messina test case. Clean Electrical Power (ICCEP), 2013 International Conference IEEE, 2013.

Cucco, A. and Umgiesser, G.: The Trapping Index: How to integrate the Eulerian and the Lagrangian approach for the computation of the transport time scales of semi-enclosed basins, Marine Pollut. Bull., 98, 210-220, 2015.

Cucco, A., Umgiesser, G., Ferrarin, C., Perilli, A., Canu, D. M., and Solidoro, C.: Eulerian and lagrangian transport time scales of a tidal active coastal basin, Ecol. Model., 220, 913-922, doi:10.1016/j.ecolmodel.2009.01.008, 2009.

Cucco, A., Sinerchia, M., Ribotti, A., Olita, A., Fazioli, L., Perilli, A., Sorgente, B., Borghini, M., Schroeder, K., and Sorgente, R.: A high-resolution real-time forecasting system for predicting the fate of oil spills in the Strait of Bonifacio (western Mediterranean Sea), Marine Pollut. Bull., 64, 1186-200, doi:10.1016/j.marpolbul.2012.03.019, 2012a.

Cucco, A., Ribotti, A., Olita, A., Fazioli, L., Sorgente, B., Sinerchia, M., Satta, A., Perilli, A., Borghini, M., Schroeder, K., and Sorgente, R.: Support to oil spill emergencies in the Bonifacio Strait, western Mediterranean, Ocean Sci., 8, 443-454, doi:10.5194/os8-443-2012, 2012b.

Cucco, A., Quattrocchi, G., Satta, A., Antognarelli, F., de Biasio, F., Cadau, E., Umgiesser, G., and Zecchetto, S.: Predictability of wind-induced sea surface transport in coastal areas, J. Geophys. Res.-Oceans, doi:10.1002/2016JC011643, 2016.

Defant, A.: Scilla e Cariddi e le correnti di marea nello Stretto di Messina, Geopis. Pura e Appl., 2, 93-112, 1940.

Defant, A.: Physical Oceanography, 2. Pergamon Press, Oxford, London-New York-Paris, 598 pp., 1961.

Dobricic, S. and Pinardi, N.: An oceanographic three-dimensional variational data assimilation scheme, Ocean Modell., 22, 89105, doi:10.1016/j.ocemod.2008.01.004, 2008.

Fazioli, L., Olita, A., Cucco, A., Tedesco, C., Ribotti, A., and Sorgente, R.: Impact of different initialisation methods on the quality 
of the sea forecasts for the Sicily Channel, J. Operat. Oceanogr., doi:10.1080/1755876X.2015.1114804, 2016.

Ferrarin, C., Bergamasco, A., Umgiesser, G., and Cucco, A.: Hydrodynamics and spatial zonation of the Capo Peloro coastal system (Sicily) through 3-D numerical modeling, J. Marine Syst., 117118, 96-107, doi:10.1016/j.jmarsys.2013.02.005, 2013a.

Ferrarin, C., Roland, A., Bajo, M., Umgiesser, G., Cucco, A., Davolio, S., Buzzi, A., Malguzzi, P., and Drofa, O.: Tidesurge-wave modelling and forecasting in the Mediterranean Sea with focus on the Italian coast, Ocean Model., 61, 38-48, doi:10.1016/j.ocemod.2012.10.003, 2013b.

Ferrarin, C., Bajo, M., Bellafiore, D., Cucco, A., De Pascalis, F., Ghezzo, M., and Umgiesser, G.: Toward homogenization of Mediterranean lagoons and their loss of hydrodiversity, Geophys. Res. Lett., 41, 5935-5941, doi:10.1002/2014GL060843, 2014.

Gaberšek, S., Sorgente, R., Natale, S., Ribotti, A., Olita, A., Astraldi, M., and Borghini, M.: The Sicily Channel Regional Model forecasting system: initial boundary conditions sensitivity and case study evaluation, Ocean Sci., 3, 31-41, 2007.

Kantha, L. H.: Barotropic tides in the global oceans from a nonlinear tidal model assimilating altimetric tides 1 . Model description and results, J. Geophys. Res., 100, 283-25, 309, 1995.

Kantha, L. H. and Clayson, C. A.: Numerical models of oceans and oceanic processes. Int. Geophys., Series, Academic Press, p. 66, 2000.

Krivosheya V. G.: Water circulation and structure in the Tyrrhenian Sea, Oceanology, Engl. Transl., 23, 166-171, 1983.

Hopkins, T. S., Salusti, E., and Settimi, D.: Tidal forcing of the water mass interface in the Strait of Messina. J. Geophys. Res.Oceans, 89, 2013-2024, doi:10.1029/JC089iC02p02013, 1984.

Mannarini, G., Turrisi, G., D’Anca, A., Scalas, M., Pinardi, N., Coppini, G., Palermo, F., Carluccio, I., Scuro, M., Cretì S., Lecci, R., Nassisi, P., and Tedesco, L.: VISIR: Technological infrastructure of an operational service for safe and efficient navigation in the Mediterranean Sea, Nat. Hazards Earth Syst. Sci. Discuss., doi:10.5194/nhess-2016-32, in review, 2016a.

Mannarini, G., Pinardi, N., Coppini, G., Oddo, P., and Iafrati, A.: VISIR-I: small vessels - least-time nautical routes using wave forecasts, Geosci. Model Dev., 9, 1597-1625, doi:10.5194/gmd9-1597-2016, 2016b

Marras, S., Cucco, A., Antognarelli, F., Azzurro, E., Milazzo, M., Bariche, M., and Domenici, P.: Predicting future thermal habitat suitability of competing native and invasive fish species: from metabolic scope to oceanographic modelling, Conserv. Physiol., 3, COU059, doi::10.1093/conphys/cou059, 2015.

Massi, M., Salusti, E., and Stocchino, C.: On the current of the Strait of Messina, Nuovo Cimento, 2, 543-548, 1979.

Melaku Canu, D., Solidoro, C., Umgiesser, G., Cucco, A., and Ferrarin, C.: Assessing confinement in coastal lagoons, Marine Pollut. Bull., 64, 2391-2398, doi:10.1016/j.marpolbul.2012.08.007, 2012.

Melaku Canu, D., Solidoro, C., Bandelj, V., Quattrocchi, G., Sorgente, R., Olita, A., Fazioli, L., and Cucco, A.: Assessment of oil slick hazard and risk at vulnerable coastal sites, Marine Pollut. Bull., 94, 84-95, doi:10.1016/j.marpolbul.2015.03.006, 2015.

Millot, C.: Circulation in the Western Mediterranean Sea, J. Marine Syst., 20, 423-442, doi:10.1016/S0924-7963(98)00078-5, 1999.

Mosetti, F.: Some news on the currents in the Strait of Messina, Boll. Oceanol. Teor. Appl., 6, 119-201, 1988.
Oddo, P., Adani, M., Pinardi, N., Fratianni, C., Tonani, M., and Pettenuzzo, D.: A Nested Atlantic-Mediterranean Sea General Circulation Model for Operational Forecasting, Ocean Sci., 5, 461473, doi:10.5194/os-5-461-2009, 2009.

Olita, A., Dobricic, S., Ribotti, A., Fazioli, L., Cucco, A., Dufau, C., and Sorgente, R.: Impact of SLA assimilation in the Sicily Channel Regional Model: model skills and mesoscale features, Ocean Sci., 8, 485-496, doi:10.5194/os-8-485-2012, 2012.

Pinardi, N. and Coppini, G.: Operational oceanography in the Mediterranean Sea: the second stage of development, Ocean Sci., 6, 263-267, doi:10.5194/os-10-263-2010, 2010.

Quattrocchi, G., Cucco, A., Antognarelli, F., Satta, A., Maicu, F., Ferrarin, C., and Umgiesser, G.: Optimal design of a lagrangian observing system for hydrodynamic surveys, J. Operat. Oceanogr., 9, 77-88 doi:10.1080/1755876X.2015.1114805, 2016.

Sannino, G., Carillo, A., Pisacane, G., and Naranjo, C.: On the relevance of tidal forcing in modelling the Mediterranean thermohaline circulation, Prog. Oceanogr., 134, 304-329, doi:10.1016/j.pocean.2015.03.002, 2015.

Simeone, S., De Falco, G., Quattrocchi, G., and Cucco, A.: Morphological changes of a Mediterranean beach over one year (San Giovanni Sinis, western Mediterranean), J. Coast. Res., 217-222, 2014.

Smagorinsky, J.: General circulation experiments with the primitive equations, Mon. Weather Rev., 91, 99-164, 1963.

Sorgente, R., Olita, A., Oddo, P., Fazioli, L., and Ribotti, A.: Numerical simulation and decomposition of kinetic energy in the Central Mediterranean: insight on mesoscale circulation and energy conversion, Ocean Sci., 7, 503-519, doi:10.5194/os-7-5032011, 2011.

Tonani, M., Pinardi, N., Dobricic, S., Pujol, I., and Fratianni, C.: A high-resolution free-surface model of the Mediterranean Sea, Ocean Sci., 4, 1-14, doi:10.5194/os-4-1-2008, 2008.

Tonani, M., Balmased, M., Bertino, L., Blockley, E., Brassington, G., Davidson, F., and Wang, H.: Status and future of global and regional ocean prediction systems, J. Oceanogr., 8, doi:10.1080/1755876X.2015.1049892, 2015.

Umgiesser, G., Canu, D. M., Cucco, A., and Solidoro, C.: A finite element model for the Venice Lagoon. Development, set up, calibration and validation, J. Marine Syst., 51, 123-145, doi:10.1016/j.jmarsys.2004.05.009, 2004.

Umgiesser, G., Ferrarin, C., Cucco, A., De Pascalis, F., Bellafiore, D., Ghezzo, M., and Bajo, M.: Comparative hydrodynamics of 10 Mediterranean lagoons by means of numerical modeling. J. Geophys. Res.-Ocean., 119, 2212-2226, doi:10.1002/2013JC009512,2014.

Vercelli, F.: Crociere per lo studio dei fenomeni dello Stretto di Messina. Il regime delle correnti e delle maree nello Stretto di Messina, Comm. Intern. del Mediterraneo, Venezia, 1-209, 1925.

Vercelli, F.: Crociere per lo studio dei fenomeni dello Stretto di Messina. Comm. Intern. del Mediterraneo, Venezia, 1-161, 1926.

Vetrano, A., Napolitano, E., Iacono, R., Schroeder, K., and Gasparini, G. P.: Tyrrhenian Sea circulation and water mass fluxes in spring 2004: Observations and model results, J. Geophys. Res., 115, C06023, doi:10.1029/2009JC005680, 2010. 